\title{
Status of Turbulence Modeling for Hypersonic Propulsion Flowpaths
}

Nicholas J. Georgiadis, Dennis A. Yoder, and Manan A. Vyas

Glenn Research Center, Cleveland, Ohio

William A. Engblom

Embry Riddle Aeronautical University, Dayton Beach, Florida 


\section{NASA STI Program . . . in Profile}

Since its founding, NASA has been dedicated to the advancement of aeronautics and space science. The NASA Scientific and Technical Information (STI) program plays a key part in helping NASA maintain this important role.

The NASA STI Program operates under the auspices of the Agency Chief Information Officer. It collects, organizes, provides for archiving, and disseminates NASA's STI. The NASA STI program provides access to the NASA Aeronautics and Space Database and its public interface, the NASA Technical Reports Server, thus providing one of the largest collections of aeronautical and space science STI in the world. Results are published in both non-NASA channels and by NASA in the NASA STI Report Series, which includes the following report types:

- TECHNICAL PUBLICATION. Reports of completed research or a major significant phase of research that present the results of NASA programs and include extensive data or theoretical analysis. Includes compilations of significant scientific and technical data and information deemed to be of continuing reference value. NASA counterpart of peer-reviewed formal professional papers but has less stringent limitations on manuscript length and extent of graphic presentations.

- TECHNICAL MEMORANDUM. Scientific and technical findings that are preliminary or of specialized interest, e.g., quick release reports, working papers, and bibliographies that contain minimal annotation. Does not contain extensive analysis.

- CONTRACTOR REPORT. Scientific and technical findings by NASA-sponsored contractors and grantees.
- CONFERENCE PUBLICATION. Collected papers from scientific and technical conferences, symposia, seminars, or other meetings sponsored or cosponsored by NASA.

- SPECIAL PUBLICATION. Scientific, technical, or historical information from NASA programs, projects, and missions, often concerned with subjects having substantial public interest.

- TECHNICAL TRANSLATION. Englishlanguage translations of foreign scientific and technical material pertinent to NASA's mission.

Specialized services also include creating custom thesauri, building customized databases, organizing and publishing research results.

For more information about the NASA STI program, see the following:

- Access the NASA STI program home page at http://www.sti.nasa.gov

- E-mail your question via the Internet to help@ sti.nasa.gov

- Fax your question to the NASA STI Help Desk at $443-757-5803$

- Telephone the NASA STI Help Desk at 443-757-5802

- Write to: NASA Center for AeroSpace Information (CASI) 7115 Standard Drive Hanover, MD 21076-1320 


\section{Status of Turbulence Modeling for Hypersonic Propulsion Flowpaths}

Nicholas J. Georgiadis, Dennis A. Yoder, and Manan A. Vyas

Glenn Research Center, Cleveland, Ohio

William A. Engblom

Embry Riddle Aeronautical University, Dayton Beach, Florida

Prepared for the

47th Joint Propulsion Conference and Exhibit

cosponsored by the AIAA, ASME, SAE, and ASEE

San Diego, California, July 31-August 3, 2011

National Aeronautics and

Space Administration

Glenn Research Center

Cleveland, Ohio 44135 


\section{Acknowledgments}

The authors would like to thank the Test Resource Management Center (TRMC) and the Test and Evaluation/Science and Technology (T\&E/S\&T) Program for their support. This work was sponsored by the TRMC T\&E/S\&T Program through the High Speed Systems Test (HSST) area (formerly APTT) and the NASA Fundamental Aeronautics Program.

Trade names and trademarks are used in this report for identification only. Their usage does not constitute an official endorsement, either expressed or implied, by the National Aeronautics and Space Administration.

This work was sponsored by the Fundamental Aeronautics Program at the NASA Glenn Research Center.

Level of Review: This material has been technically reviewed by technical management.

Available from

NASA Center for Aerospace Information 7115 Standard Drive

Hanover, MD 21076-1320
National Technical Information Service 5301 Shawnee Road Alexandria, VA 22312 


\title{
Status of Turbulence Modeling for Hypersonic Propulsion Flowpaths
}

\author{
Nicholas J. Georgiadis, Dennis A. Yoder, and Manan A. Vyas \\ National Aeronautics and Space Administration \\ Glenn Research Center \\ Cleveland, Ohio 44135 \\ William A. Engblom \\ Embry Riddle Aeronautical University \\ Dayton Beach, Florida 32114
}

This report provides an assessment of current turbulent flow calculation methods for hypersonic propulsion flowpaths, particularly the scramjet engine. Emphasis is placed on Reynolds-averaged Navier-Stokes (RANS) methods, but some discussion of newer methods such as Large Eddy Simulation (LES) is also provided. The report is organized by considering technical issues throughout the scramjet-powered vehicle flowpath including laminar-to-turbulent boundary layer transition, shock wave / turbulent boundary layer interactions, scalar transport modeling (specifically the significance of turbulent Prandtl and Schmidt numbers) and compressible mixing. Unit problems are primarily used to conduct the assessment. In the combustor, results from calculations of a direct connect supersonic combustion experiment are also used to address the effects of turbulence model selection and in particular settings for the turbulent Prandtl and Schmidt numbers. It is concluded that RANS turbulence modeling shortfalls are still a major limitation to the accuracy of hypersonic propulsion simulations, whether considering individual components or an overall system. Newer methods such as LES-based techniques may be promising, but are not yet at a maturity to be used routinely by the hypersonic propulsion community. The need for fundamental experiments to provide data for turbulence model development and validation is discussed.

\section{Nomenclature}

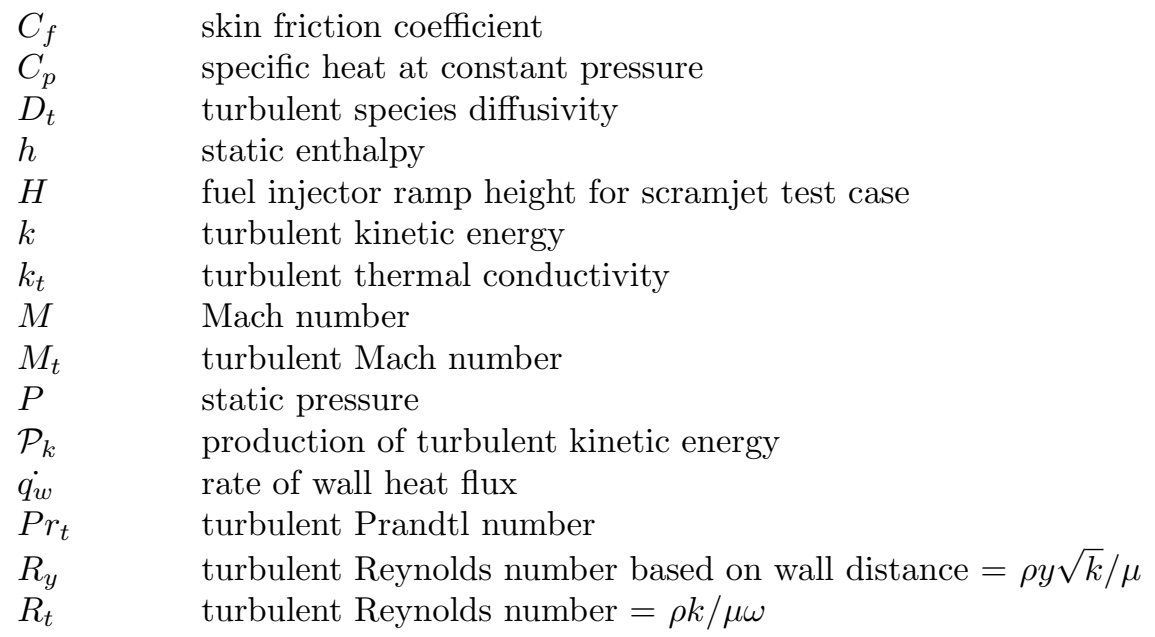




$\begin{array}{ll}R e_{x} & \text { plate Reynolds number } \\ R e_{\nu} & \text { vorticity-based Reynolds number }=\rho y^{2} \Omega / \mu \\ s & \text { streamline coordinate } \\ S_{i j} & \text { rate of strain tensor } \\ S c_{t} & \text { turbulent Schmidt number } \\ S t & \text { Stanton number } \\ t & \text { time } \\ T & \text { static temperature } \\ T_{r} & \text { temperature ratio } \\ T_{t} & \text { stagnation temperature } \\ T_{w} & \text { wall static temperature } \\ U_{j} & \text { velocity vector } \\ U_{\infty} & \text { freestream velocity } \\ W_{i j} & \text { vorticity tensor } \\ x, y, z & \text { Cartesian coordinates } \\ y^{+} & \text {wall normal coordinate } \\ \epsilon & \text { turbulent dissipation rate } \\ \epsilon_{s} & \text { solenoidal turbulent dissipation rate } \\ \mu & \text { dynamic viscosity } \\ \mu_{t} & \text { dynamic eddy viscosity } \\ \omega & \text { specific turbulent dissipation rate }=\epsilon / k \\ \Omega & \text { vorticity magnitude } \\ \phi & \text { fuel equivalence ratio } \\ \rho & \text { density } \\ \rho_{\infty} & \text { freestream density } \\ \tau_{i j}^{T} & \text { turbulent stress tensor } \\ & \end{array}$

\section{Introduction}

Flowpaths within hypersonic propulsion systems, in particular the scramjet engine, are characterized by several aerodynamic and thermodynamic features which are very difficult for currently available computational fluid dynamics (CFD) methods to calculate accurately. At the same time, experiments cannot provide all of the details of scramjet flows because of the difficulties in simulating actual operating conditions in ground experiments and making appropriate measurements in flight tests. As a result, the need for competent CFD methods to be used in conjunction with experiments is high, in order to successfully carry out hypersonic research and development programs, as outlined in detail by Drummond et $\mathrm{al}^{1}$ and Tishkoff et $\mathrm{al}^{2}$ One CFD modeling area that has remained extremely challenging, yet very critical to the success of hypersonic propulsion system simulations is turbulence modeling, which is the focus of this paper.

Scramjet powered hypersonic vehicles are among the most integrated vehicle / propulsion system configurations of all aircraft. Nevertheless, we may identify flow features specific to the primary propulsion system components that provide the greatest turbulence modeling challenges, as identified in Fig. 1. For many hypersonic vehicles, the entire forebody beginning with the leading edge forms part of the engine inlet. Here boundary layer transition has a large effect on the thickness of the boundary layers that enter the enclosed portion of the scramjet engine and also on the the thermal properties of the vehicle forebody. Knowledge of the boundary layer state is important enough that programs such as HyperX / X-43 have implemented forced transition locations via boundary layer trips. ${ }^{3,4}$

Within the inlet and isolator, shockwave/boundary layer interactions severely complicate the flow, and provide many challenges to turbulence modeling efforts. Within the combustor, the complexities are numerous. These include three-dimensional turbulent mixing in the presence of a chemically reacting flow, recirculating flow at the locations of fuel injection, heat transfer at the combustor walls, compressibility effects, and continued shockwave / boundary layer interactions. Further downstream in the expansion system, the flow may still be reacting and the complexities are similar to those at the beginning of the combustor region.

The practical state-of-the-art in CFD for hypersonic propulsion flowpath analyses during the past two 
decades has been Reynolds-averaged Navier-Stokes (RANS) methods, typically using two-equation eddy viscosity closures such as k- $\omega$ or k- $\epsilon$ models. In terms of more advanced RANS techniques, some limited attempts have been made to use algebraic Reynolds stress models, but substantial improvement over the linear two-equation eddy viscosity approaches has not been demonstrated. There have not been many attempts to use full Reynolds-stress closures for scramjet analyses. The flow features described in the preceding paragraph all provide major challenges to the most commonly used two-equation eddy viscosity RANS techniques. Transition models coupled to RANS are highly empirical at best, and have only been shown to have potential applicability at high freestream turbulence levels, which is not the case in actual flight simulations. For hypersonic vehicle inlets, RANS methods have been shown to be quite deficient for calculating the details of shockwave/boundary layer interactions. Isolator flowfields frequently contain several shock boundary layer interactions. In ramjet mode, this separated flow enters the combustor creating a complex flowfield that no RANS models can accurately compute.

The complexities occurring farther downstream in the combustor and expansion system, namely high temperatures, compressibility effects, recirculating flow in the regions of fuel injection, and other threedimensional flow features, further overwhelm currently practical CFD capabilities. Baurle ${ }^{5}$ provides a comprehensive overview of turbulent reacting methods for supersonic combustion while Ebrahami ${ }^{6}$ addresses $^{-}$ validation challenges for high speed combustion problems from scramjets to rockets. Turbulent chemistry interactions are obviously crucial in these regions, yet no RANS-based techniques have been shown to accurately represent the actual flow state. Constant values for the turbulent Prandlt and Schmidt number are typically used to extend the RANS-based eddy viscosity used in the momentum equations to the turbulent heat transport and species transport in the energy and individual species transport equations, respectively. This is known to be a significant limitation, ${ }^{5,7}$ and while some efforts have been underway in recent years to develop more sophisticated RANS-based models for such scalar transport, not enough testing and calibration has been performed to date to determine the potential of these techniques.

Beyond RANS-based methods, large eddy simulation (LES) techniques and hybrid RANS-LES techniques have received significant attention over the past decade for application to aerodynamic flow analyses. While progress has been made in developing and using such techniques, especially for flows away from walls, LES-based techniques cannot be considered a mature science, free of modeling parameters that need to be set by the analyst. Effects of grid sensitivity are fundamentally different from RANS-based techniques. In RANS, it is the expectation that as one refines a computational grid, a grid-independent solution is achieved. In contrast for LES, as the grid is refined, typically more small turbulent structures are resolved instead of modeled, and the solution can indeed be expected to change. In the subsonic combustor community, LES techniques have been shown to have some promise, ${ }^{8}$ in particular for flows where wall effects can be considered small, and where turbulent velocity scales are on the order of the mean flow velocity. In a scramjet combustor, however, the situation is different, as the core flow velocity is still of appreciable magnitude, and wall boundary layer effects are important. References 9 and 10 have demonstrated some of the earliest application of LES-based methods to scramjet combustors. While LES-based methods have promise for calculating the largest scales of turbulence, chemical reactions occur at the microscale, so the subgrid scale modeling used in LES for scramjet simulations (or any combustor for that matter) is very important. Some research into developing more accurate subgrid scale closures to handle turbulence /chemistry interactions is underway, ${ }^{11}$ but such methods are far from being considered mature enough to be applicable to practical hypersonic propulsion system analyses.

In this paper, the chief modeling challenges briefly outlined in this introduction are addressed. The current practical state-of-the-art in RANS-based techniques is emphasized, utilizing some of our own recent experiences. Our efforts utilized the Wind-US code ${ }^{12-14}$ which is a production RANS solver with several available turbulence models. Discussion of more computationally intensive techniques such as LES, including hybrid RANS-LES approaches, will be provided. Suggestions for the required research to result in improvements to these methods will be described. A discussion of experimental efforts that would aid modeling efforts will also be provided.

\section{RANS Turbulence Modeling}

For nearly two decades, the practical state-of-the-art in RANS turbulence modeling has employed twoequation eddy viscosity turbulence models. In linear eddy viscosity models, the Boussinesq approximation is used to relate the turbulent Reynolds stress to the mean rate of strain tensor through a turbulent (or eddy) 
viscosity:

$$
\tau_{i j}^{T}=\mu_{t}\left(2 S_{i j}-\frac{2}{3} \frac{\partial u_{k}}{\partial x_{k}} \delta_{i j}\right)-\frac{2}{3} \rho k \delta_{i j}
$$

The rate of strain is tensor, $S_{i j}$, is given by:

$$
S_{i j}=\frac{1}{2}\left(\frac{\partial u_{j}}{\partial x_{i}}+\frac{\partial u_{i}}{\partial x_{j}}\right)
$$

It is beyond the scope of this paper to describe all two-equation models that are in use today. A detailed list of several RANS turbulence models that have been used in hypersonic simulations is presented in Ref. 15. It should be noted that the vast majority of the literature concerning validation and comparison of RANS turbulence models has not been in the hypersonic regime, but at much slower speeds, particularly subsonic and transonic. A majority of the two-equation turbulence models in use are either $k-\epsilon$ or $k-\omega$ formulations, which we focus on here. While not discussed here, a model that has received attention for high speed flows in recent years in the $k-\zeta$ (enstrophy) model as described in Refs. 16-18. Here we describe in some detail one turbulence model that is widely used, and has been utilized for the majority of our work in recent years. This model is the Shear-Stress Transport (SST) two-equation turbulence formulation of Menter. ${ }^{19}$ The SST model has been shown to be robust and relatively accurate for a broad range of flows, including wall boundary layers and free shear layer regions. The SST model is a two-layer model which employs the $k-\omega$ model of Wilcox ${ }^{20}$ in the inner region of boundary layers and switches to a $k-\epsilon$ model in the outer region of boundary layers and in mixing regions. The outer $k-\epsilon$ model is transformed to provide a second set of $k-\omega$ equations with a blending function used to transition between the two sets of equations.

$$
\begin{aligned}
\frac{\partial \rho k}{\partial t}+\frac{\partial \rho U_{j} k}{\partial x_{j}} & =\mathcal{P}_{k}-\beta^{*} \rho \omega k+\frac{\partial}{\partial x_{j}}\left(\left(\mu+\sigma_{k} \mu_{t}\right) \frac{\partial k}{\partial x_{j}}\right) \\
\frac{\partial \rho \omega}{\partial t}+\frac{\partial \rho U_{j} \omega}{\partial x_{j}} & =\frac{\alpha}{\nu_{t}} \mathcal{P}_{k}-\beta \rho \omega^{2}+\frac{\partial}{\partial x_{j}}\left(\left(\mu+\sigma_{\omega} \mu_{t}\right) \frac{\partial \omega}{\partial x_{j}}\right)+\left(1-F_{1}\right) 2 \rho \sigma_{\omega 2} \frac{1}{\omega} \frac{\partial k}{\partial x_{j}} \frac{\partial \omega}{\partial x_{j}} \\
\mathcal{P}_{k} & =\min \left[2 \mu_{t} S_{i j} S_{i j}-\frac{2}{3}\left(\mu_{t} S_{m m}-\rho k\right) S_{n n} ; \mu_{t} \Omega^{2}\right] \\
F_{1}^{*} & =\tanh \left(\arg _{1}^{4}\right) \\
F_{4} & =\exp \left(-\left(R_{y} / 120\right)^{8}\right) \\
F_{1} & =\max \left(F_{1}^{*}, F_{4}\right) \\
\arg _{1} & =\min \left(\max \left(\frac{\sqrt{k}}{\beta^{*} \omega y} ; \frac{500 \nu}{\omega y^{2}}\right) ; \frac{4 \rho \sigma_{\omega 2} k}{C D_{k \omega} y^{2}}\right) \\
C D_{k \omega} & =\max \left(2 \rho \sigma_{\omega 2} \frac{1}{\omega} \frac{\partial k}{\partial x_{j}} \frac{\partial \omega}{\partial x_{j}} ; 1.0 \times 10^{-20}\right)
\end{aligned}
$$

and from these the turbulent viscosity is given as

$$
\begin{aligned}
\mu_{t} & =\min \left(\alpha^{*} \frac{\rho k}{\omega} ; \frac{a_{1} \rho k}{\Omega F_{2}}\right) \\
F_{2} & =\tanh \left(\arg _{2}^{2}\right) \\
\arg _{2} & =\min \left(2 \frac{\sqrt{k}}{\beta^{*} \omega y} ; \frac{500 \nu}{\omega y^{2}}\right)
\end{aligned}
$$

The constants $\left(\phi_{1}\right)$ associated with these equations for the inner, $k-\omega$, model are:

$$
\begin{array}{llll}
\sigma_{k 1}=0.85, & \beta_{1}^{*}=0.09 \cdot \frac{5 / 18+\left(R_{t} / 8\right)^{4}}{1+\left(R_{t} / 8\right)^{4}}, & \alpha_{1}^{*}=\frac{.025+R_{t} / 6}{1+R_{t} / 6}, & \\
\sigma_{\omega 1}=0.5, & \beta_{1}=0.075, & \alpha_{1}=\frac{5}{9} \cdot \frac{0.1+R_{t} / 2.7}{1+R_{t} / 2.7}, & a_{1}=0.31
\end{array}
$$


and the constants $\left(\phi_{2}\right)$ for the transformed $k-\epsilon$ model are:

$$
\begin{array}{llll}
\sigma_{k 2}=1.0, & \beta_{2}^{*}=0.09, & \alpha_{2}^{*}=1, & \\
\sigma_{\omega 2}=0.856, & \beta_{2}=0.0828, & & \alpha_{2}=0.4403,
\end{array}
$$

These constants are blended using the same switching function, $F_{1}$ that is found in the model equations such that $\phi=F_{1} \phi_{1}+\left(1-F_{1}\right) \phi_{2}$ for any of the given parameters.

The SST turbulence model has become popular for its ability to handle separated flows and complex geometry in the near wall region due to the strengths of the $k-\omega$ model, while maintaining the characteristics of the $k-\epsilon$ model to be more accurate in free shear layers.

In eddy viscosity models such as the SST formulation, the ultimate quantity that is used in the momentum equations to model the turbulent stresses is the eddy viscosity, $\mu_{t}$. In most RANS codes, a constant turbulent Prandtl number is used to extend the eddy viscosity to model the turbulent thermal transport via the relation:

$$
\operatorname{Pr}_{t}=\mu_{t} C_{p} / k_{t}
$$

The turbulent species diffusivity is extended from the eddy viscosity in a similar manner via the turbulent Schmidt number:

$$
S c_{t}=\mu_{t} C_{p} / D_{t}
$$

In most applications at low Mach numbers and without reactions or significant heat transfer effects, the air is treated as a calorically perfect gas; a constant turbulent Prandtl number on the order of unity is typically used and no species transport equations are solved. However, the turbulent Prandtl and Schmidt numbers have significant effects for supersonic combustion problems as will be discussed in a later section.

Beyond two-equation models, full Reynolds-stress closures, or second moment closures as they are sometimes referred to, offer a more complete representation of the three-dimensional turbulent stress field. However, the improvements in accuracy over linear two-equation models have not been shown to be sufficiently high enough to justify the additional computational cost. ${ }^{21}$ As a result, the international CFD community has not broadly accepted the usage of full Reynolds stress closures, even with the known limitations of linear eddy-viscosity models. As a compromise beyond two-equation viscosity models, there has been some work to develop and investigate non-linear explicit algebraic stress models (EASMs). Unlike linear two-equation models, EASM formulations are sensitive to turbulent stress anisotropies and have a direct relation to the full Reynolds stress model. ${ }^{22}$ As a result, EASM models have the capability to include more relevant flow physics than the linear models. However, they are also solved using a two-equation approach and as a result are not significantly more computationally expensive than linear two-equation models.

The turbulent stress tensor of the EASM (for both $k-\epsilon$ and $k-\omega$ ) is:

$$
\begin{array}{r}
\tau_{i j}^{T}=2 \mu_{t}\left\{S_{i j}-\frac{1}{3} S_{k k} \delta_{i j}+\left[a_{2} a_{4}\left(S_{i k} W_{k j}-W_{i k} S_{k j}\right)\right.\right. \\
\left.\left.-2 a_{3} a_{4}\left(S_{i k} S_{k j}-\frac{1}{3} S_{k l} S_{l k} \delta_{i j}\right)\right]\right\}-\frac{2}{3} \rho k \delta_{i j}
\end{array}
$$

where $S_{i j}$ was defined previously in Eq. 2 and $W_{i j}$ is:

$$
W_{i j}=\frac{1}{2}\left(\frac{\partial u_{i}}{\partial x_{j}}-\frac{\partial u_{j}}{\partial x_{i}}\right)
$$

The eddy viscosity, $\mu_{t}$ is:

$$
\mu_{t}=C_{\mu}^{*} \rho k \tau=-\rho k \alpha_{1}
$$

where the turbulent time scale is $\tau=1 / \omega=k / \epsilon$. The quantity $\alpha_{1} / \tau$ is equivalent to $-C_{\mu}^{*}$ and is obtained from the solution to a cubic equation at every point in the flow field. The closure constants, $a_{2}, a_{3}, a_{4}$, and entire solution procedure are described in Refs. 23 and 24. The form of the $k-\omega$ model used as the underlying two-equation model for the EASM described here is provided in Ref. 25.

In the following sections, we consider the performance of RANS turbulence modeling for component or subset problems that exhibit the turbulence modeling-dominated features found within the hypersonic propulsion system flowpath as described in the introduction and shown schematically in Fig. 1. We begin with a discussion of laminar-to-turbulent boundary transition. Consideration of shock wave / turbulent 
boundary layer interactions, which dominate the flow within the scramjet isolator but are pervasive to the entire scramjet propulsion flowpath, are considered next. Moving toward the rear of the propulsion flowpath, consideration of turbulence modeling factors in the combustor and exhaust system are presented in the last section.

\section{Forebody/Inlet Transition Modeling}

Hypersonic flight vehicles frequently have boundary layers with significant laminar regions on vehicle forebodies and inlet surfaces because of the low freestream disturbances and low densities characteristic of the altitudes that such vehicles fly within. While flight tests can reproduce these atmospheric conditions, scaling issues due to Reynolds number affect the ability to reproduce the effects of boundary layer state, and in particular the point of transition. Ground test facilities frequently have freestream turbulence levels that are high enough to affect the transition point. Whereas the mechanism of transition in free flight is usually modal growth, the high freestream turbulence experienced by ground test articles frequently leads to bypass transition, in which the transition to turbulent flow is dictated by large freestream disturbances. In this section, we consider a RANS-based bypass transition model. It is generally agreed that RANS-based techniques are not applicable to modal growth situations.

Details of the formulation presented here are provided in Ref. 26. The model is based on the SST turbulence model and was built starting from a previous SST-based transition model. ${ }^{27-29}$ Several modifications were made to enable: (1) consistent solutions regardless of flow field initialization procedure and (2) fully turbulent flow beyond the transition region. In the following, we highlight only the key aspects of the implementation of the bypass transition model. Building upon the SST turbulence model, the key modification is made to the production term in the turbulent kinetic energy equation:

$$
\frac{\partial \rho k}{\partial t}+\frac{\partial \rho U_{j} k}{\partial x_{j}}=P T M \cdot \mathcal{P}_{k}-\beta^{*} \rho \omega k+\frac{\partial}{\partial x_{j}}\left(\left(\mu+\sigma_{k} \mu_{t}\right) \frac{\partial k}{\partial x_{j}}\right)
$$

where PTM is termed the "production term multiplier." The $\omega$ equation is not modified.

The final form of the transition model that is recommended based on the work of Ref. 26 is:

$$
\begin{aligned}
& P T M=1-0.94(P T M 1+P T M 2) F_{3} \tanh \left(\left(y^{+} / 17\right)^{2}\right) \\
& F_{3}=e^{-\left(\frac{R_{t}}{3}\right)^{2}}\left(1-P\left(R_{t}\right)\right)+\frac{1}{2} P\left(R_{t}\right) \\
& P\left(R_{t}\right)=\frac{2.5}{\sqrt{2 \pi}} e^{\frac{-\left(R_{t}-3\right)^{2}}{2}} \\
& P T M 1=1-C_{P T M 1} \begin{cases}{\left[\left(3.28 \times 10^{-4}\right) R e_{v}-\left(3.94 \times 10^{-7}\right) R e_{v}^{2}+\left(1.43 \times 10^{-10}\right) R e_{v}^{3}\right] ;} & R e_{v}<1000 \\
{\left[0.12+\left(1.00 \times 10^{-5} R e_{v}\right] ;\right.} & R e_{v}>1000\end{cases} \\
& P T M 2= \begin{cases}-|K|^{0.4} \frac{R e_{v}}{80} ; & K<0 \\
0 ; & K>0\end{cases} \\
& 1.0 \leq C_{P T M 1} \leq 2.0 \quad \text { (Recommended range) }
\end{aligned}
$$

where $R e_{v}$ is the vorticity-based Reynolds number, $R_{t}$ is the turbulent Reynolds number, and the pressure gradient parameter, $K$, is given by

$$
K=-\frac{\mu}{\rho^{2} U^{3}}\left[1-M^{2}\right] \frac{d p}{d s}
$$

In Refs. 28 and 29, PTM2 was formulated for flows with significant internal flow pressure gradients, and specifically for flows within low pressure turbine stages. In all cases examined in this work and that of Ref. 26, where flows with significant pressure gradients were not examined, PTM2 was not found to be significant.

This model is intended for flows where bypass transition is the key transition mechanism as opposed to transition dictated by modal growth. Validation of the new transition model was performed for flows ranging from incompressible to hypersonic conditions. 
Figure 2 shows a comparison of simulations for a widely used data set for incompressible transition flow over a flat plate(referred to as the T3A test case $^{30}$ ). The fully turbulent SST solution shows the rapid transition (much closer to an entirely turbulent flow) that provided the motivation for the present work. It does a poor job of accurately capturing the early laminar behavior and the transition location which would lead to incorrect results for the drag on this flat plate. For the transition model solutions, the effect of the key parameter, $C_{P T M 1}$, is to control the transition onset location. As with nearly all RANS-based transition prediction schemes, the width of the calculated transition region is shorter than indicated by experimental data. The solution with $C_{P T M 1}=2.0$ captures the transition onset location best while decreasing $C_{P T M 1}$ to 1.0 (the default value from original formulation) captures the end of the transition zone (i.e. where fully turbulent flow is realized) best.

Hypersonic transitional flows present unique challenges in both modeling and experimentation. To baseline the present model's ability to predict transitional behavior in hypersonic conditions, it was validated against transition data taken on sharp nose cones in the AEDC tunnel B at Mach 7.93. ${ }^{31}$ The simulation is performed on a $7^{\circ}$ half-angle cone. As in the experiment, the wall temperature was set at $0.42 T_{t}$, where $T_{t}$ is the freestream stagnation temperature. Several unit Reynolds numbers $(R e / m)$ were evaluated in Ref. 31 to provide a complete scan of the transition region. These data show good agreement for transition location across a range of $R e / m$, allowing the simulation to use only one, $\approx 6.8 \mathrm{E} 6 \mathrm{Re} / \mathrm{m}$, corresponding closely with the center of the experimental range. Inflow conditions are calculated to match those of Ref. 31. Insight from Ref. 32 indicated that an inlet freestream turbulence intensity of $1.25 \%$ was appropriate for AEDC tunnel B.

Figure 3 shows the Stanton number ( $S t$ ), as defined by Ref. 31 and as shown in Eq. 27, versus Reynolds number for the SST model alone, the SST transition model using $C_{P T M 1}=1.0$ and $C_{P T M 1}=2.0$, and the experimental data.

$$
S t=\dot{q_{w}} /\left(\rho_{\infty} U_{\infty}\left(h\left(T_{t}\right)-h\left(T_{w}\right)\right)\right)
$$

As in the incompressible case, the predicted behavior is overly abrupt. However, the model accurately captures the minimum heat transfer value, corresponding to transition onset for $C_{P T M 1}=2.0$ and the location where the flow becomes fully turbulent for $C_{P T M 1}=1.0$.

The transition model solutions are a marked improvement over the SST model alone, which vastly overpredicts the heat transfer by indicating a fully turbulent state from the leading edge of the test article. For a model in a high-speed wind tunnel that has a significant laminar region, the error due to transition onset can be quite large. The total heat transfer integrated over the length of the cone differs by $38.7 \%$ between the standard (fully turbulent) SST model and the SST-based transition model with $C_{P T M 1}=1.0$. Accurately capturing this behavior is especially important when trying to evaluate thermal properties and heat transfer behavior near the tip of a hypersonic vehicle. The large discrepancy in heat transfer rates indicated by the two models would substantially alter the vehicle's predicted temperature profile.

While the transition model presented here demonstrates some promise for bypass transition, it is emphasized that a general RANS-based predictive technique for the modal growth situation that is more important in free flight has not been demonstrated nor is likely feasible. LES is likely not a candidate either, because the transition process is dominated by amplification of initially very small disturbances, which is in contrast to the LES philosophy of calculating the largest turbulent scales while modeling the smallest scales. In the long run, direct numerical simulation (DNS) probably offers the best prospects for such a predictive capability. In the interim, techniques such as $e^{N}$ methods, in which stability theory is used to predict the location of transition, ${ }^{33-35}$ will remain the realistic option.

\section{Shock Wave Turbulent Boundary Layer Interactions}

The shock wave / turbulent boundary layer interaction (SWTBLI) is a very common phenomena that has significant effects throughout the hypersonic propulsion system flowpath. The problem has been studied extensively over the past few decades in laboratory experiments and in computational fluid dynamics (CFD) efforts. While gains in understanding of the underlying fluid dynamics of SWTBLI have been made, research continues into understanding the complex interaction of a shock wave with a turbulent boundary layer. In a typical SWTBLI, the adverse pressure gradient induced by the shock system causes a flow separation that frequently is unsteady and three-dimensional. Without question, control of SWTBLI has yet to be mastered. While there have been numerous CFD studies, there is not a single approach that has been identified as optimal for calculation of SWTBLI. 
For practical aerodynamic analyses that contain one or more SWTBLIs as is the case for a scramjet isolator, RANS is still the only feasible approach. More recently, large eddy simulation (LES) and hybrid RANS-LES techniques have been investigated for application to the SWTBLI problem, but typically have been restricted to small unit problems, as applying an LES-based technique to a more complex system (i.e. aircraft inlet) involving SWTBLIs is still largely prohibitive due to the range of scales involved. Knight and Degrez ${ }^{36}$ and Knight et $\mathrm{al}^{37}$ provide comprehensive overviews of a broad range in CFD methods as applied to SWTBLIs, in particular those investigated under AGARD and RTO working groups. Consideration of both RANS and LES methods is made. Reference 38 focuses on an assessment of RANS-based methods while a survey of LES-based approaches as applied to SWTBLIs is presented in Edwards. ${ }^{39}$ The overall conclusions of these survey papers is that RANS methods are inherently unable to calculate some of the crucial features of SWTBLI, in particular the unsteadiness of the shock system and separated flow. In addition, the three dimensional features are also troublesome for RANS-based techniques. LES-based techniques may be promising, but neither sufficient maturity of these techniques nor experience using them has been realized.

In an inlet or isolator the shocks closest to the leading edge of the vehicle have the highest approach Mach number. Further downstream, the shocks may occur at lower approaching Mach number, but the boundary layers are typically thicker and may have already been subject to effects of upstream SWTBLIs. Such is the case in scramjet isolators.

We applied several two-equation models including eddy-viscosity models and EASMs to a Mach 5 SWBLI problem in the current work. Mach number contours for an SST Wind-US solution are provided in Fig. 4. Comparisons of several solutions using linear two-equation turbulence models and EASMs with experimental data from Ref. 40 are provided in Fig. 5. It may be observed that the linear $k-\epsilon$ model solution provides poor agreement with experimental data. While the $k-\epsilon$ based EASMs, with and without compressibility corrections, marginally improve upon the linear $k-\epsilon$ solution, the largest improvement is obtained by using the $k-\omega$ formulations, including the Menter SST model. The $k-\omega$ EASMs provide improvement just past the shock impingement point. The solution obtained with the SST model also provides reasonable agreement in the post-shock region, with somewhat lower calculated skin friction than the experimental data and the other $k-\omega$ models (linear and EASM).

A recent workshop considering CFD calculations for a set of SWTBLI cases was held in conjunction with the 48th American Institute of Aeronautics and Astronautics (AIAA) Aerospace Sciences Meeting. An overview of the workshop objectives is presented in Benek ${ }^{41}$ with a summary of overall findings presented in Benek. ${ }^{42}$ Several investigators contributed solutions to this workshop. Contributions included RANS and LES-based computations. DeBonis et $\mathrm{al}^{43}$ provides a comprehensive assessment of the CFD calculations, including uncertainty analysis of the submitted CFD results and experimental data obtained for the same configurations. Hirsch ${ }^{44}$ examined some of the CFD trends, in particular effects of turbulence modeling, RANS versus LES, and numerical schemes submitted by several investigators and includes the results from our efforts described here.

One of two SWTBLI configurations considered in the workshop was a test case obtained at the Institut Universitaire des Systemes Thermiques Industriels (IUSTI) in Marseille, France. ${ }^{45}$ The experimental data was utilized in the European Union SWTBLI research project referred to as UFAST. ${ }^{46}$ The UFAST experiments utilized an 8 degree shock generator which spanned the entire width of the tunnel with an approaching Mach 2.25 flow. The supply stagnation pressure was $50.5 \mathrm{kPa}$ and the stagnation temperature was $293 \mathrm{~K}$. A schematic of the experimental configuration representing that used in the UFAST experiments is shown in Fig. 6 as taken from DeBonis et al. ${ }^{43}$ Particle Image Velocimetry (PIV) was used in all cases to characterize the interaction region, with both mean flow velocities and turbulent statistics obtained.

For this test case, we utilized the Menter SST k- $\omega$ and k- $\omega$ based EASM two-equation models and the one-equation model due to Spalart and Allmaras. ${ }^{47,48}$ Axial velocity contours obtained for the UFAST test case are shown in Fig. 7. The oblique wave originating from the sharp leading edge of the shock generator may be observed, along with the SWTBLI region centered about $x=320 \mathrm{~mm}$. The complex interaction on the top of the tunnel actually results in a flow separation that is much larger than that in the focused SWTBLI region on the bottom.

The experimental data was collected within the region focused around the bottom wall interaction. Axial velocity contours for the UFAST test case using the three turbulence modeling approaches are compared to the experimental PIV measurements in Fig. 8. The CFD solution slices represent the same physical domain, with the same contour levels as the experimental data. The CFD solutions were interpolated to the same physical locations where the PIV data were taken, as was required by the organizers of the AIAA workshop, 
for purposes of computing differences between solutions and experimental data. ${ }^{43}$ Examining these contours, the extent of the adverse pressure gradient effects indicated by the Menter SST solution are larger than the other solutions and experimental data. Further comparisons of the CFD solutions and experimental data are made for the axial velocity profiles at four axial locations in Fig. 9. One may observe that the CFD solutions plotted do not go all of the way to the wall, and again this is due to interpolation of the CFD results to the PIV measurement locations.

The comparisons in Fig. 9 show the same trends as indicated by the contour plots of Fig. 8. In particular, the size of the flow separation indicated by the SST solution is greater than that indicated by the experimental data or the other turbulence models. It appears that the SA and ASM models do not predict as large a SWTBLI region as the experimental data. These results are very similar to those reported for SA and SST by Bhagwandin and DeSpirito. ${ }^{49}$ They also considered a $\mathrm{k}-\epsilon$ model which produced solutions that highly underestimated the effect of the SWBLI. This is generally the expected performance of $\mathrm{k}-\epsilon$ models in separated or adverse pressure gradient flows. ${ }^{21}$

\section{Combustor / Exhaust System Modeling}

For several years, the University of Virginia (UVA) has conducted research on a benchmark scramjet combustor, shown schematically in Fig. 10, to investigate dual-mode ramjet/scramjet engine behavior. ${ }^{50-52}$ This configuration consists of a two-dimensional convergent-divergent nozzle providing a Mach 2 flow to a rectangular isolator. An electric heater is used to provide clean air at approximately $1200 \mathrm{~K}$ to the test article. To examine test media effects, water vapor and carbon dioxide delivery systems may be used to replicate the vitiated air levels typical of combustion heated facilities simulating Mach 5 flight. For reference, the key stations through the UVA configuration are listed in table 1. Downstream of the isolator, an unswept ramp contains a single round fuel injector which provides unheated hydrogen to a combustor section. The burned flow then enters a divergent nozzle and exhausts to the freestream. The fuel injector geometry is a convergent-divergent nozzle. We have applied RANS based calculations to this configuration, ${ }^{12,53,54}$ with much of the focus on determining the capability of CFD to replicate differences between clean air and vitiated air on engine performance as a function of fuel equivalence ratio. Gupte et $\mathrm{al}^{55}$ used finite element analysis to examine the thermal-structural response of the UVA test article and found substantial effects of the thermal deformation on the predicted flowfield when comparing CFD solutions from the baseline to the thermally deformed configuration.

\begin{tabular}{lc} 
Station & $\mathrm{x} / \mathrm{H}$ \\
\hline Isolator Entrance & -45 \\
Fuel Injection Plane & 0 \\
Nozzle Exit & 57 \\
\hline
\end{tabular}

Table 1. Key positions for UVA scramjet configuration

Most recently, the results of Vyas et $\mathrm{al}^{54}$ demonstrated the ability to qualitatively reproduce the equivalence ratios where the combustor operation switched from ramjet to scramjet mode in the experiments of Rockwell et al. ${ }^{52}$ In all of these experiments, the equivalence ratios were relatively low, on the order of 0.5 or less, in comparison to the typical equivalence ratios on the order of unity that a scramjet intended for actual flight will experience. Variants of the baseline UVA scramjet combustor flow have been developed, as discussed in Goyne et al, ${ }^{56}$ to enable higher equivalence ratios in anticipation of planned flight tests.

A major difficulty in drawing solid conclusions of CFD-to-experiment comparisons of scramjet predictions is that frequently the only quantity available for comparison is surface pressure measurements as a function of axial position in the scramjet flowpath. In CFD, several factors can contribute to significant changes in the pressure distribution, i.e. turbulence model selection, settings for the turbulent Prandtl and Schmidt numbers, chemical kinetics choice, wall temperature and/or heat transfer modeling. Typically an analyst will make a selection for all of these model settings, and then vary one of the parameters, such as the turbulent Schmidt number, to optimize the CFD generated pressure distribution until it passes most closely through the experimental pressure distribution. While this is the current "state-of-practice," optimizing such settings for one scramjet configuration at one operating point does not guarantee the same settings will be optimal 
at other operating points, say with different freestream inflow conditions and fuel equivalence ratios. Over a period of several years, the efforts discussed in Refs. 12,53,54 considered effects of turbulence model selection, settings for the turbulent Prandtl and Schmidt numbers, and chemical kinetics modeling. We also worked closely with the experimentalists, who made significant efforts to carefully measure heat transfer through the scramjet walls, to model the wall thermal conditions as closely as possible.

The discussion here focuses on findings specific to turbulence modeling. Figure 11 shows Mach number contours in the UVA scramjet flowpath for the fuel off $(\phi=0.0)$ case using the Chien $k-\epsilon$ model. The top plot shows contours from the facility nozzle entrance through isolator, combustor and exhaust nozzle. The middle plot focuses on the region near the end of the isolator and combustor, while the bottom plot extends from the combustor to the exhaust nozzle exit plane. Supersonic flow exits from the facility nozzle, through the combustor, and into the expansion nozzle with no pressure rise in the combustor, which would occur for fueled cases. In contrast to a flight vehicle nozzle, where by design the flow would continue to expand through the exhaust nozzle, the flow in the UVA experiments is overexpanded due to limitations in the overall system nozzle pressure ratio, and a shock system with flow separation may be observed near the exhaust nozzle exit.

Figure 12 shows a comparison of RANS solutions obtained using the Menter SST model and the Chien $k-\epsilon$ model. Through most of the flowpath, the pressure distributions are very similar, but in the last half of the exhaust nozzle, the SST pressure distribution deviates from the experimental data and the $k-\epsilon$ solution. This is the result of the SST solution separating much farther upstream in the nozzle. As discussed in the SWTBLI section, typically $k-\epsilon$ models are not considered a good choice for flows with separations, and the SST model has developed a broad reputation for performing better in such situations. However, as shown in the SWTBLI results, it appears that SST overreacts in moderate to highly separated flows situations. This may be in part due to the actual shear stress limiter term active within the Menter SST model, but the performance is generally similar to other $k-\omega$ models.

Our initial set of calculations simulating an entire sweep in fuel equivalence ratios, as reported in Bhagwandin et al, ${ }^{53}$ used the SST model and 7 -species, 8-step $H_{2}$-air kinetics due to Evans and Shexnayder ${ }^{57}$ modified to include third body efficiencies other than unity, as taken from the model of Jachimowski. ${ }^{58}$ After obtaining the result shown in Fig. 12, which was not expected, we completed an additional sweep in equivalence ratios for both clean and vitiated air as reported in Vyas et al, ${ }^{54}$ using 9 -species, 13 -step $H_{2}$-air kinetics due to Peters and Rogg ${ }^{59}$ and the Chien k- $\epsilon$ model. The Peters and Rogg model was selected for the subsequent studies because the complete kinetics set was developed to investigate vitiated air. These latter calculations were able to reproduce the experimentally observed "mode transition" or point at which the core flow entering the combustor region changed from subsonic (ramjet) to supersonic (scramjet). Figure 13 provides a comparison of Mach number contours for two cases, both at the same fuel equivalence ratio, $\phi=0.26$, but in one case the supply flow was clean air and the other has vitiated air with 10 percent water vapor per mole. It may be observed that the clean air case is in ramjet mode while the vitiated air case is in scramjet mode. These results are largely due to chemical kinetics effects, although to obtain this qualitative agreement with experimental results on the equivalence ratio where mode transition occurred required close calibration of the choices in turbulence model settings, including turbulent Prandtl and Schmidt numbers. Figure 14 shows the strong sensitivity of the solutions to turbulent Schmidt number.

We emphasize that these choices may not be optimal for all scramjet configuration simulations. In particular, the performance of the $k-\epsilon$ model may be considered somewhat fortuitous, and in general is not considered an optimal choice for flows with separations. The conclusion here is that the "state-of-practice" in RANS as applied to complete scramjet systems requires calibration of the modeling parameters for one case, i.e. selecting fixed values for the turbulent Prandtl and Schmidt numbers and then trusting that the trends of the solutions will remain qualitatively accurate at other operating points. As mentioned previously, it is difficult to draw definitive conclusions on the validity of a particular CFD modeling choice for a complex system such a scramjet when only pressure distributions as a function of axial position are available. For this reason, usually unit problems are considered to investigate the behavior of individual model settings.

\section{Scalar Transport Modeling}

A broadly used experiment for validation of supersonic reacting flows is that of Burrows and Kurkov. ${ }^{60}$ A schematic of their experimental setup is shown in Fig. 15. Despite the fact that these experiments were performed a number of years ago, the data obtained for this hydrogen-vitiated air test case remains widely used today. Using the 8-step kinetics of Evans and Shexnayder discussed previously, we present 
results here that exhibit the sensitivity of the solutions to settings for the turbulent Prandtl and Schmidt numbers. Figures 16 and 17 provide temperature contours in the mixing section which illustrate the effects of variation in these scalar transport settings on the ignition point. The ignition point in the experiment was approximately $x=22 \mathrm{~cm}$. Exit plane contours are shown in Fig. 18. While both quantities have considerable effects, the turbulent Schmidt number effects are more pronounced. The Schmidt number controls the turbulent species transport, and considering the Arrhenius rate form of the chemical kinetics used in most RANS combustion simulations as well as the actual physical process requiring sufficient reactants to be present for combustion to occur, it is not surprising that the turbulent Schmidt number has such an important effect on the combustion behavior.

Unfortunately the optimal turbulent Schmidt number and turbulent Prandtl number for one case are not likely optimal for another. Further, the current common practice of setting constant values to $P r_{t}$ and $S c_{t}$ for modeling scalar transport is very likely inadequate for the complex flows occurring in scramjet systems. This finding has been been reported elsewhere, such as in Ref. 7. Work has been underway to investigate variable Prandtl/Schmidt number formulations, or "scalar variance methods" to be used for improving the modeling of turbulent heat and mass transport in scramjets and high speed reacting jets such as those described in Refs. 61-65. The treatment of turbulent-chemistry interactions, such as those involving probability density function (PDF) formulations ${ }^{66,67}$ is beyond the scope of this paper. However, one study that demonstrated a variable Schmidt number model incorporated with a PDF approach is described in Ref. 68. While these efforts are promising, the methods are not mature enough yet to be in broad use by the scramjet community. Sufficient experimental data to thoroughly develop and validate these methods is also not available, yet very much needed.

\section{Compressible Mixing}

In the scramjet combustor and into the exhaust nozzle, turbulent mixing is highly three dimensional and subject to compressibility effects. In this section we briefly discuss the status of modeling compressible mixing. A number of experiments may be found in the literature concerning planar mixing layers and effects of compressibility on mixing layer growth rates. In recent years, most computational and experimental research efforts has focused on jet flows, driven by aircraft noise considerations. For the high speed compressible jet problem, one of the most widely used data sets is from the benchmark experiments performed at the NASA Langley Research Center (LaRC) Jet Noise Laboratory by Seiner et al. ${ }^{69}$ These experiments investigated an axisymmetric water-cooled Mach 2 nozzle. The nozzle operated at fully expanded conditions for this series of cases. In our studies, the turbulence models examined were the Menter SST and Chien k- $\epsilon$ formulations. In addition, these two models were used with and without the Sarkar compressibility correction, ${ }^{70,71}$ as shown in Eq. 28.

$$
\epsilon=\epsilon_{s}\left(1+\alpha M_{t}^{2}\right)
$$

and the turbulent Mach number is defined as:

$$
M_{t}=\sqrt{2 k} / a
$$

where $\epsilon_{s}$ is the solenoidal dissipation rate solved in the dissipation equation for the k- $\epsilon$ model where $\omega=\epsilon / \mathrm{k}$. The coefficient, $\alpha$, is set to the default value of 1.0 here for use with both turbulence models. The Sarkar compressibility correction increases the rate of turbulent kinetic energy dissipation and then lowers the resultant turbulent viscosity. Compressibility corrections such as the Sarkar formulation, are most commonly employed for free shear layers or jets. For wall bounded flows, compressibility effects are not considered to be important for Mach numbers less than about 5, as discussed by Wilcox. ${ }^{21}$ Rumsey examined compressibility corrections applied to $k-\omega$ models for hypersonic boundary layers in Ref. 72 .

In Dembowski and Georgiadis, ${ }^{73}$ a comparison of computations to experiments were made for all of the operating points, with variations in jet stagnation temperature that were measured in the experiments of Ref. 69. Results are presented for the highest temperature case with nozzle plenum stagnation temperature set to $1370 \mathrm{~K}$ in Fig. 19. For this and other operating points, the Chien k- $\epsilon$ solution and SST solutions with no compressibility corrections provide similar solutions with faster jet mixing than indicated by the experimental data. The Chien and SST model results obtained with the Sarkar compressibility correction indicate much longer potential cores and slowest initial mixing of any of the solutions for all of the temperatures investigated. In all of the cases shown in Ref. 73 where several jet operating temperatures were investigated, solutions 
obtained with the compressibility correction overpredict the potential core length, as shown for the highest temperature case considered here. In results for supersonic jet calculations shown by Gross et al ${ }^{74,75}$ the performance of SST with and without the Sarkar correction is analogous to the results obtained here. As shown in Ref. 76, the potential core length behavior observed here for the uncorrected models is not the same for lower Mach number jets, where two-equation turbulence model results generally indicated longer potential core lengths, and implied slower initial mixing rates, than found experimentally. As a result, while compressibility corrections could be tailored, for example via the Sarkar coefficient, $\alpha$, for a particular case, there are not enough physics in such models to accurately capture compressibility effects. The conclusion here is that compressible mixing is yet another area in which RANS turbulence modeling improvements are still necessary.

\section{LES-based Methods for Combustor and Exhaust System}

With all of these limitations of RANS-based techniques for the scramjet combustor and exhaust nozzle regions, there is hope that LES and hybrid RANS-LES may offer better prospects for improving the ability to calculate regions dominated by turbulent mixing. There have been significant efforts underway in developing and applying LES for mixing problems, especially turbulent jets issuing from aircraft exhaust nozzles. However there are a number of unresolved issues in LES that significantly affect the accuracy of turbulent jet flows and other mixing dominated problems. There have been some limited attempts to use LES for scramjet combustors, as in Refs. 9 and 10. In the combustor, the LES problem of accurately capturing turbulent-chemistry interactions is analogous to the RANS problem. Some research into techniques such as filtered density functions, the LES analogy to the RANS usage of PDFs, are being examined. ${ }^{11,77}$

Considering the scramjet system as a whole, the need to accurately treat both the wall bounded regions and the mixing layers away from the walls provides difficult challenges. At first impression, hybrid RANSLES methods seem to be a promising solution to this problem, and indeed they should be and are being explored. ${ }^{78-80}$ However the interface region where RANS switches to LES, is one of the most significant challenges. In aerodynamic flows, hybrid RANS-LES has found success where the RANS regions are demarcated from the LES regions and some physical feature is responsible for the instabilities that generate and sustain turbulence in the LES regions. ${ }^{81}$ In the scramjet, frequently a flameholder with a rearward facing step can serve as the physical mechanism behind which large scale eddies may be generated, to drive the necessary unsteadiness of the LES region. Countering this, however, are the large values of eddy viscosity convected from the thick isolator boundary layers calculated with RANS, which serve to damp the unsteadiness in the computation.

\section{Experimental Validation Data}

The need for fundamental experiments to provide data for method development and validation is very high. As discussed previously, while full scramjet simulations are informative, it is very difficult to perform validation of specific CFD modeling features for complete scramjet systems. One reason is that historically only static pressure instrumentation is employed in scramjet experiments. Further, it is nearly impossible to parametrically isolate the benefits of one particular modeling feature, whether it be turbulence modeling, chemical kinetics modeling, or heat transfer, when the effects of the modeling limitations in the others is unknown. For these reasons, unit problems are more useful in model development and validation. While there are a number of such unit problem experiments reported in the literature, most of the data available consists of mean flow measurements. Improvements in turbulence modeling for hypersonic propulsion requires turbulent statistical data from simultaneous measurements of velocities, temperatures, and species concentrations.

One current effort addressing this need is the US National Center for Hypersonic Combined Cycle Propulsion. ${ }^{82}$ This center is developing and using advanced experiments and diagnostics such as Coherent AntiStokes Raman Scattering (CARS), PIV, Rayleigh techniques, and Planar Induced Flourescence (PLIF) to obtain more detailed data including turbulent statistics and the simultaneous measurements of velocities, temperatures, and species concentrations. This center is also developing advanced turbulent calculation methods targeted at the supersonic combustion problem, including RANS, LES, and hybrids. NASA's Fundamental Aeronautics Program, the United States Air Force Office of Scientific Research and the Test Resource Management Center's Test and Evaluation/Science and Technology (T\&E/S\&T) Program are also sponsoring experimental research efforts from geometrically simple unit flow problems to fully integrated systems and also sponsoring computational method development and validation efforts. With hypersonic 
funding historically very cyclical in the United States, it is hoped that a sustained effort will be possible, as the research needs are great.

Some recommendations for specific experimental data needs that are not currently being broadly addressed are as follows: In the area of SWTBLIs, advanced measurement techniques such as PIV have been recently applied to fundamental experiments, such as those described earlier in this paper. However, nearly all of these experiments have been conducted in facilities with small tunnel cross sectional areas, where sidewall effects frequently contaminate the focus SWTBLI region. It would be highly desirable to utilize an experimental rig where such sidewall effects could be eliminated. PIV has become a powerful and broadly used experimental technique. Obtaining high accuracy in regions such as the beginning of a jet shear layer, where the turbulent flow state is far from equilibrium, is quite a challenge. However, it is this region where both RANS turbulence models and direct calculation methods (i.e. DNS and LES) need data for method development and validation.

Thermal boundary layers obviously have significant effects on hypersonic propulsion flowpath aerothermodynamics. While heat transfer and surface temperature measurements are being made in some select configurations, this is the exception rather than the rule. Such measurements are very difficult to make, but crucial in attempts to accurately represent the thermal boundary layer states as well as identifying potential thermal deformation which in turn can alter the flowpath cross sectional area and aerodynamics. For the combustor, detailed mappings of the turbulent flow state for velocities, temperatures, and species concentrations are necessary. While some fundamental experiments are attempting to obtain these quantities, perhaps revisiting an experiment such as the Burrows-Kurkov test case (which only provided mean flow quantities) with these more modern experimental techniques (i.e. PIV, CARS, and PLIF) would greatly assist modelers in determining if a particular modeling enhancement was actually improving the fidelity of the correct turbulent flow physics.

\section{Conclusions}

This paper presents one group's perspective on the current state of turbulent flow calculation methods for hypersonic propulsion flowpaths. It is not intended to serve as a comprehensive review of all computational techniques in use today, but does discuss key issues throughout the vehicle propulsion flowpath. These include laminar-to-turbulent boundary layer transition, shock wave / turbulent boundary layer interactions, and modeling of the combustor and exhaust system. Emphasis was placed on Reynolds-averaged NavierStokes (RANS) methods, although prospects of newer methods such as Large Eddy Simulation (LES) based techniques were also provided. It is concluded that RANS turbulence modeling shortfalls are still a major limitation to the accuracy of hypersonic propulsion simulations, whether considering individual components or an overall system. Newer methods such as LES-based techniques may be promising, but are not yet at a maturity to be used routinely by the hypersonic propulsion community.

RANS turbulence model development in the past decade has been minimal for all aerodynamic regimes. Most of the programmatic support for turbulent calculation techniques has been toward LES-based techniques. While the broader CFD community will likely be using LES more in the future as computing power continues to improve, there is still a need in the foreseeable future for better RANS-based techniques. The subsonic aircraft community, while also examining hybrid RANS-LES techniques, is currently beginning to revisit pure RANS models because of the importance to aerodynamic predictions of quantities such as vehicle drag. Support for improving some of the modeling shortfalls identified in this paper for hypersonic propulsion flowpaths is also warranted. Finally, more detailed experimental data to help guide modeling improvements is also needed. 


\section{References}

${ }^{1}$ Drummond, J. P., Cockrell, C. E., Pellett, G. L., Diskin, G. S., Auslender, A. H., Exton, R. J., Guy, R. W., Hoppe, J. C., Puster, R. L., Rogers, R. C., Trexler, C. A., and Voland, R. T., "Hypersonic Air Breathing Propulsion - An Aerodynamics, Aerothermodynamics, and Acoustics Competency White Paper," NASA TM 2002-211951, Nov. 2002.

${ }^{2}$ Tishkoff, J. M., Drummond, J. P., Edwards, T., and Nejad, A. S., "Future Direction of Supersonic Combustion Research: Air Force/NASA Workshop on Supersonic Combustion," AIAA Paper 97-1017, Jan. 1997.

${ }^{3}$ Berry, S. A., DiFulvio, M., and Kowalkowski, M. K., "Forced Boundary-Layer Transition on X-43 (Hyper-X) in NASA LaRC 31-Inch Mach 10 Air Tunnel," NASA TM 2000-210315, 2002.

${ }^{4}$ Berry, S. A., Auslender, A. H., Dilley, A. D., and Calleja, J. F., "A Hypersonic Boundary-Layer Trip Development for Hyper-X," Journal of Spacecraft and Rockets, Vol. 38, No. 6, Nov. 2001, pp. 853-864.

${ }^{5}$ Baurle, R. A., "Modeling of High Speed Reacting Flows: Established Practices and Future Challenges," AIAA Paper 2004-267, Jan. 2004.

${ }^{6}$ Ebrahami, H. B., "An Overview of Computational Fluid Dynamics for Application to Advanced Propulsion Systems," AIAA Paper 2004-2370, June 2004.

${ }^{7}$ Baurle, R. and Eklund, D., "Analysis of Dual-Mode Hydrocarbon Scramjet Operation at Mach 4-6.5," Journal of Propulsion and Power, Vol. 18, No. 5, Sept. 2002, pp. 990-1002.

${ }^{8}$ Pitsch, H., Desjardins, O., Balarac, G., and Ihme, M., "Large Eddy Simulation of Turbulent Reacting Flow," Progress in Aerospace Sciences, Vol. 44, No. 6, Aug. 2008, pp. 466-478.

${ }^{9}$ Fureby, C., "LES Modeling of Combustion for Propulsion Applications," Proceedings of the Royal Society A, Vol. 367, July 2009, pp. 2957-2969.

${ }^{10}$ Berglund, M., Fureby, C., Sabel'nikov, V., and Tegner, J., "On the Influence of Finite Rate Chemistry in LES of SelfIgnition in Hot Confined Supersonic Airflow," European Space Agency Special Report ESA SP-659, 2008.

${ }^{11}$ Givi, P., "Filtered Density Function for Subgrid Scale Modeling of Turbulent Combustion," AIAA Journal, Vol. 44, No. 1, Jan. 2006, pp. 16-23.

${ }^{12}$ Georgiadis, N. J., Yoder, D. A., Towne, C. E., Engblom, W. A., Bhagwandin, V., Power, G. D., Lankford, D. W., and Nelson, C. C., "Wind-US Physical Modeling Improvements to Complement Hypersonic Testing and Evaluation," AIAA Paper 2009-193, Jan. 2009.

${ }^{13}$ Nelson, C. C. and Power, G. D., "CHSSI Project CFD-7: The NPARC Alliance Flow Simulation System," AIAA Paper 2001-0594, Jan. 2001.

${ }^{14}$ Nelson, C., "An Overview of the NPARC Alliance's Wind-US Flow Solver," AIAA Paper 2010-27, Jan. 2010.

${ }^{15}$ Roy, C. J. and Blottner, F. G., "Review and assessment of turbulence models for hypersonic flows," Progress in Aerospace Sciences, Vol. 42, 2006, pp. 469-530.

${ }^{16}$ Robinson, D. F., Harris, J. E., and Hassan, H. A., "Unified Turbulence Closure Model for Axisymmetric and Planar Free Shear Layer Flows," AIAA Journal, Vol. 33, No. 12, Dec. 1995, pp. 2324-2331.

${ }^{17}$ Robinson, D. F. and Hassan, H. A., "Modeling Turbulence Without Damping Functions Using k- $\zeta$ Model," AIAA Paper 97-2312, June 1997.

${ }^{18}$ Alexopoulos, G. A. and Hassan, H. A., "A k- $\zeta$ (Enstrophy) Compressible Turbulence Model for Mixing Layers and Wall Bounded Flows," AIAA Paper 96-2039, June 1996.

${ }^{19}$ Menter, F. R., "Zonal Two Equation $k-\omega$ Turbulence Models for Aerodynamic Flows," AIAA Journal, Vol. 32, No. 8, Aug. 1994, pp. 1598-1605.

${ }^{20}$ Wilcox, D. C., "Reassessment of the Scale-Determining Equation for Advanced Turbulence Models," AIAA Journal, Vol. 26, No. 11, Feb. 1988, pp. 1299-1310.

${ }^{21}$ Wilcox, D. C., Turbulence Modeling for CFD, DCW Industries, 2nd ed., 1998.

${ }^{22}$ Rumsey, C. L. and Gatski, T. B., "Summary of EASM Turbulence Models in CFL3D with Validation Test Cases," NASA TM 2003-212431, June 2003.

${ }^{23}$ Rumsey, C. L. and Gatski, T. B., "Recent Turbulence Model Advances Applied to Multielement Airfoil Computations," Journal of Aircraft, Vol. 38, No. 5, Sept. 2001, pp. 904-910.

${ }^{24}$ Rumsey, C. L., Gatski, T. B., and Morrison, J. H., "Turbulence Model Predictions of Strongly Curved Flow in a U-Duct," AIAA Journal, Vol. 38, No. 8, Aug. 2000, pp. 1394-1402.

${ }^{25}$ Yoder, D. A., "Initial Evaluation of an Algebraic Reynolds Stress Model for Compressible Turbulent Shear Flows," AIAA Paper 2003-0548, Jan. 2003.

${ }^{26}$ Denissen, N. A., Yoder, D. A., and Georgiadis, N. J., "Implementation and Validation of a Laminar-to-Turbulent Transition Model in the Wind-US Code," NASA TM 2008-215451, Sept. 2008.

${ }^{27}$ Langtry, R., A Correlation-Based Transition Model using Local Variables for Unstructured Parallelized CFD Codes, Ph.D. thesis, University of Stuttgart, 2006.

${ }^{28}$ Langtry, R. B. and Sjolander, S. A., "Prediction of Transition for Attached and Separated Shear Layers in Turbomachinery," AIAA Paper 2002-3641, July 2002.

${ }^{29}$ Menter, F., Ferreira, J. C., Esch, T., and Konno, B., "The SST Turbulence Model with Improved Wall Treatment for Heat Transfer Predictions in Gas Turbines," Proceedings of the International Gas Turbine Congress - IGTC2003-TS-059, Nov. 2003.

${ }^{30}$ Savill, A. M., "Some Recent Progress in the Turbulence Modeling of By-pass Transition," Near-Wall Turbulent Flows, edited by C. S. R.M.C. So and B. Launder, 1993, pp. 829-848.

${ }^{31}$ Kimmel, R. L., "The Effect of Pressure Gradients on Transition Zone Length in Hypersonic Boundary Layers," Journal of Fluids Engineering, Vol. 119, Mar. 1997, pp. 36-41.

${ }^{32} \mathrm{McDaniel}, \mathrm{R}$. D. and Hassan, H. A., "Role of Bypass Transition in Conventional Hypersonic Facilities," AIAA Paper 2001-0209, Jan. 2001. 
${ }^{33}$ Reshotko, E., "Transition Issues at Hypersonic Speeds," AIAA Paper 2006-707, Jan. 2006.

${ }^{34}$ Reshotko, E., "Is $\operatorname{Re}_{\theta} / M_{\theta}$ a Meaningful Transition Criteria?" AIAA Paper 2007-0943, Jan. 2007.

${ }^{35}$ van Ingen, J. L., "The $e^{N}$ method for transition prediction. Historical review of work at TU Delft," AIAA Paper 20083830, June 2008.

${ }^{36}$ Knight, D. and Degrez, G., "Shock Wave / Boundary Layer Interactions in High Mach Number Flows - A Critical Survey of Current CFD Prediction Capability," AGARD AR-319, Vol. 2, 1998.

${ }^{37}$ Knight, D., Yan, H., Panaras, A. G., and Zheltovodov, A., "Advances in CFD Prediction of Shock Wave Turbulent Boundary Layer Interactions," Progress in Aerospace Sciences, Vol. 39, No. 2, Feb. 2003, pp. 121-184.

${ }^{38}$ Zheltovodov, A. A., "Some Advances in Research of Shock Wave Turbulent Boundary Layer Interactions," AIAA Paper 2006-0496, Jan. 2006.

${ }^{39}$ Edwards, J. R., "Numerical Simulations of Shock/Boundary Layer Interactions Using Time-Dependent Modeling Techniques: A Survey of Recent Results," Progress in Aerospace Sciences, Vol. 44, No. 6, Aug. 2008, pp. 447-465.

${ }^{40}$ Schulein, E., "Optical Skin Friction Measurements in Short-Duration Facilities," AIAA Paper 2004-2115, June 2004.

${ }^{41}$ Benek, J., "Overview of the 2010 AIAA Shock Boundary Layer Interaction Workshop," AIAA Paper 2010-4821, Jan. 2010.

${ }^{42}$ Benek, J. and Babinsky, H., "Lessons Learned from the 2010 AIAA Shock Boundary Layer Interaction Workshop," AIAA Paper 2010-4825, Jan. 2010

${ }^{43}$ DeBonis, J. R., Oberkampf, W. L., Wolf, R. T., Orkwis, P. D., Turner, M. G., and Babinsky, H., "Assessment of CFD Models for Shock Boundary-Layer Interaction," AIAA Paper 2009-4823, Jan. 2010.

${ }^{44}$ Hirsch, C., "SBLI Lessons Learned - CFD Simulations of Two Test Cases," AIAA Paper 2010-4824, Jan. 2010.

${ }^{45}$ Dupont, P., Piponniau, S., Sidorenko, A., and Debieve, J., "Investigation by Particle Image Velocimetry Measurements of Oblique Shock Reflection with Separation," AIAA Journal, Vol. 46, No. 6, June 2008, pp. 1365-1370.

${ }^{46}$ Unsteady Effects in Shock Wave Induced Separation, edited by P. Doerffer, C. Hirsch, J.-P. Dussauge, H. Babinsky, and G. Barakos, Springer, 2010.

${ }^{47}$ Spalart, P. R. and Allmaras, S. R., "A One-Equation Turbulence Model for Aerodynamic Flows," AIAA Paper 92-0439, Jan. 1992.

${ }^{48}$ Spalart, P. R. and Allmaras, S. R., "A One-Equation Turbulence Model for Aerodynamic Flows," La Recherche Aerospatiale, , No. 1, 1994, pp. 5-21.

${ }^{49}$ Bhagwandin, V. A. and DeSpirito, J., "Numerical Prediction of Supersonic Shock Boundary-Layer Interaction," AIAA Paper 2011-859, Jan. 2011.

${ }^{50}$ Goyne, C. P., McDaniel, J. C., Quagliaroli, T. M., Krauss, R. H., and Day, S. W., "Dual-Mode Combustion of Hydrogen in a Mach 5 Continuous-Flow Facility," Journal of Propulsion and Power, Vol. 17, No. 6, Nov. 2001, pp. 1313-1318.

${ }^{51}$ Goyne, C. P., Rodriguez, C. G., McDaniel, J. C., Krauss, R. H., and McClinton, C. R., "Experimental and Numerical Study of a Dual-Mode Scramjet Combustor," Journal of Propulsion and Power, Vol. 22, No. 3, May 2006, pp. 481-489.

${ }^{52}$ Rockwell, R. D., Goyne, C. P., Haw, W., Krauss, R. H., McDaniel, J. C., , and Trefny, C. J., "Experimental Study of Test Medium Vitiation Effects on Dual-Mode Scramjet Mode Transition," AIAA Paper 2010-1126, Jan. 2010.

${ }^{53}$ Bhagwandin, V., Engblom, W. A., and Georgiadis, N. J., "Numerical Simulation of Hydrogen-Fueled Dual-Mode Scramjet Engine Using Wind-US," AIAA Paper 2009-5382, Jan. 2009.

${ }^{54}$ Vyas, M. A., Engblom, W. A., Georgiadis, N. J., Trefny, C. J., and Bhagwandin, V., "Numerical Simulation of Vitiation Effects on a Hydrogen-Fueled Dual-Mode Scramjet," AIAA Paper 2010-1127, Jan. 2010.

${ }^{55}$ Gupte, A. A., Engblom, W. A., Goyne, C. P., and Rockwell, R. D., "Effect of Thermally Induced Deformation in UVa Supersonic Combustion Facility," AIAA Paper 2011-503, Jan. 2011.

${ }^{56}$ Goyne, C. P., Cresci, D., and Fetterhoff, T. P., "Short Duration Propulsion Test and Evaluation (HyV) Program," AIAA Paper 2009-7926, Oct. 2010.

${ }^{57}$ Evans, J. and Shexnayder, C., "Influence of Chemical Kinetics and Unmixedness on Burning in Supersonic Hydrogen Flames," AIAA Journal, Vol. 18, No. 2, Feb. 1979, pp. 805-811.

${ }^{58}$ Jachimowski, C., "An Analysis of Combustion Studies in Shock Expansion Tunnels and Reflected Shock Tunnels," NASA TP 3224, July 1992.

59 "Reduced Kinetic Mechanisms for Applications in Combustion Systems," Lecture Notes in Physics, edited by N. Peters and B. Rogg, Springer Verlag, 1993.

${ }^{60}$ Burrows, M. and Kurkov, A., "Analytical and Experimental Study of Supersonic Combustion of Hydrogen in a Vitiated Airstream," NASA TM-X 2828, Sept. 1973

${ }^{61}$ Brinckman, K. W., Calhoon, W. H., and Dash, S. M., "Scalar Fluctuation Modeling for High-Speed Aeropropulsive Flows," AIAA Journal, Vol. 45, No. 5, May 2007, pp. 1036-1046.

${ }^{62}$ Brinckman, K. W., Calhoon, W. H., Mattick, S. J., Tomes, J., and Dash, S. M., "Scalar Variance Model Validation for High-Speed Variable Composition Flows," AIAA Paper 2006-715, Jan. 2006.

${ }^{63}$ Kenzakowski, D. C., Papp, J., and Dash, S. M., "Evaluation of Advanced Turbulence Models and Variable Prandtl/Schmidt Number Methodology for Propulsive Flows," AIAA Paper 2000-0885, Jan. 2000.

${ }^{64}$ Chidambaram, N., Dash, S. M., and Kenzakowski, D. C., "Scalar Variance Transport in the Turbulence Modeling of Propulsive Jets," AIAA Paper 99-0235, Jan. 1999.

${ }^{65}$ Xiao, X., Hassan, H. A., and Baurle, R. A., "Modeling Scramjet Flows with Variable Turbulent Prandtl and Schmidt Numbers," AIAA Journal, Vol. 45, No. 6, June 2007, pp. 1415-1423.

${ }^{66}$ Hsu, A. T., Tsai, Y. L. P., and Raju, M. S., "Probability Density Function Approach for Compressible Turbulent Reacting Flows," AIAA Journal, Vol. 32, No. 7, July 1994, pp. 1407-1415.

${ }^{67}$ Baurle, R. A., Hsu, A. T., and Hassan, H. A., "Assumed and Evolution Probability Density Functions in Supersonic Turbulent Combustion Calculations," Journal of Propulsion and Power, Vol. 11, No. 6, Nov. 1995, pp. 1132-1138. 
${ }^{68}$ Keistler, P. G., Gaffney, R. L., Xiao, X., and Hassan, H. A., "Turbulence Modeling for Scramjet Applications," AIAA Paper 2005-5382, June 2005.

${ }^{69}$ Seiner, J. M., Ponton, M. K., Jansen, B. J., and Lagen, N. T., "The Effect of Temperature on Jet Noise Emission," AIAA Paper 92-02-046, 1992.

${ }^{70}$ Sarkar, S., Erlebacher, G., Hussaini, M. Y., and Kreiss, H. O., "The Analysis and Modeling of Dilatational Terms in Compressible Turbulence," Journal of Fluid Mechanics, Vol. 227, 1991, pp. 473-493.

${ }^{71}$ Sarkar, S. and Lakshmanan, B., "Application of a Reynolds Stress Turbulence Model to the Compressible Shear Layer," AIAA Journal, Vol. 29, No. 5, May 1991, pp. 743-749.

${ }^{72}$ Rumsey, C. L., "Compressibility Considerations for k- $\omega$ Turbulence Models in Hypersonic Boundary-Layer Applications," Journal of Spacecraft and Rockets, Vol. 47, No. 1, Jan. 2010, pp. 11-20.

${ }^{73}$ Dembowski, M. A. and Georgiadis, N. J., "An Evaluation of Parameters Influencing Jet Mixing Using the WIND NavierStokes Code," NASA TM 2002-211727, Aug. 2002.

${ }^{74}$ Gross, N., Blaisdell, G. A., and Lyrintzis, A. S., "Evaluation of Turbulence Model Corrections for Supersonic Jets using the OVERFLOW Code," AIAA Paper 2010-4604, June 2010.

${ }^{75}$ Gross, N., Blaisdell, G. A., and Lyrintzis, A. S., "Analysis of Modified Compressibility Corrections for Turbulence Models," AIAA Paper 2011-279, Jan. 2011.

${ }^{76}$ Georgiadis, N. J. and DeBonis, J. R., "Navier-Stokes Analysis Methods for Turbulent Jet Flows with Application to Aircraft Exhaust Nozzles," Progress in Aerospace Sciences, Vol. 42, No. 5, July 2006, pp. 377-418.

${ }^{77}$ Madnia, C. K., Jaberi, F. A., and Givi, P., "Large Eddy Simulations of Heat and Mass Transport in Turbulent Flows," Handbook of Numerical Heat Transfer, edited by W. J. Minkowycz, E. M. Sparrow, and J. Y. Murthy, John Wiley and Sons, 2009.

${ }^{78}$ Edwards, J. R., Boles, J. A., and Baurle, R. A., "LES/RANS Simulation of a Supersonic Reacting Wall Jet," AIAA Paper 2010-370, Jan. 2010.

${ }^{79}$ Boles, J. A., Edwards, J. R., and Baurle, R. A., "Large-Eddy/Reynolds-Averaged Navier-Stokes Simulations of Sonic Injection into Mach 2 Crossflow," AIAA Journal, Vol. 48, No. 7, July 2010, pp. 1444-1456.

${ }^{80}$ Fulton, J. A., Edwards, J. R., Goyne, C. P., McDaniel, J. C., and Rockwell, R., "Numerical Simulation of Flow in a Dual-Mode Scramjet Combustor," AIAA Paper 2011-3714, June 2011.

${ }^{81}$ Georgiadis, N. J., Rizzetta, D. P., and Fureby, C., "Large-Eddy Simulation: Current Capabilities, Recommended Practices, and Future Research," AIAA Journal, Vol. 48, No. 8, Aug. 2010, pp. 1772-1784.

${ }^{82} \mathrm{McDaniel}$, J. C., Chelliah, H., Goyne, C. P., Edwards, J. R., Givi, P., and Cutler, A. D., "US National Center for Hypersonic Combined Cycle Propulsion: An Overview," AIAA Paper 2009-7280, Oct. 2009.

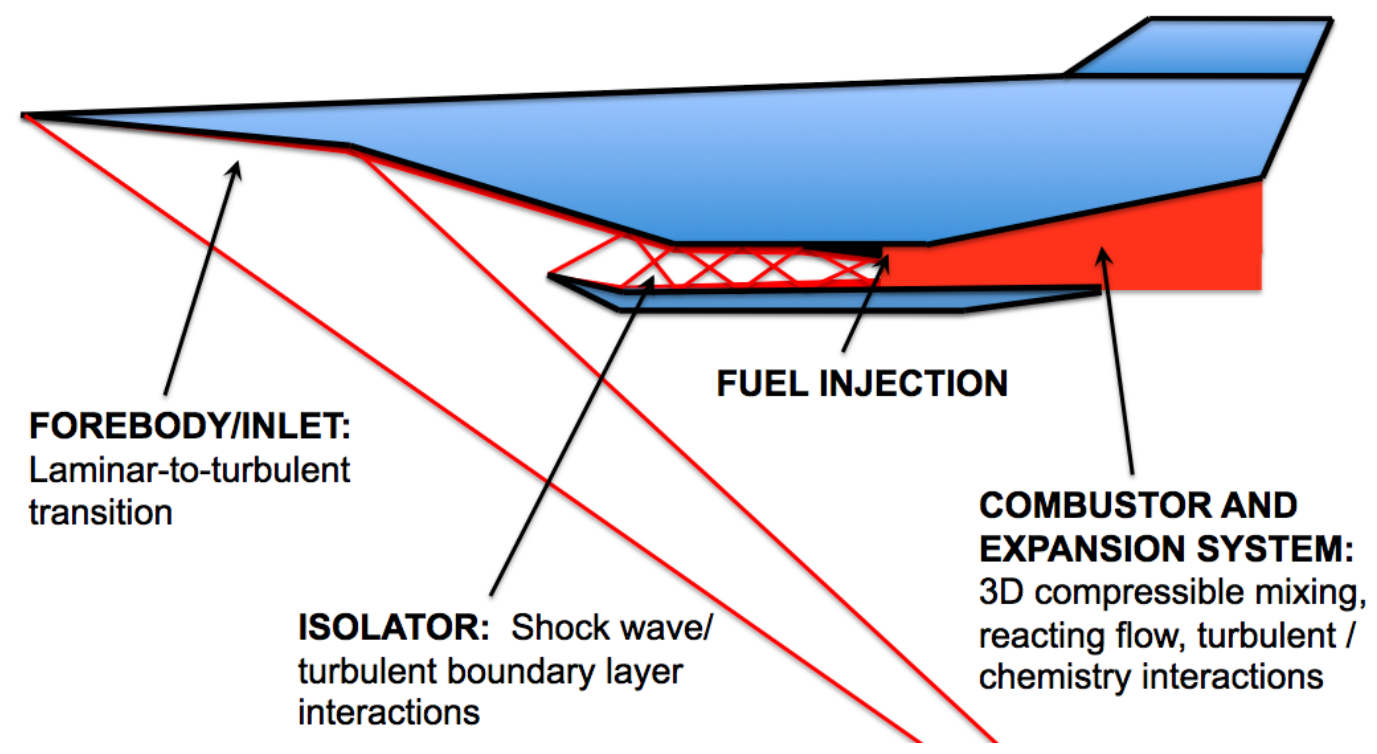

Figure 1. Schematic of scramjet-powered hypersonic vehicle with key turbulent flow physics. 


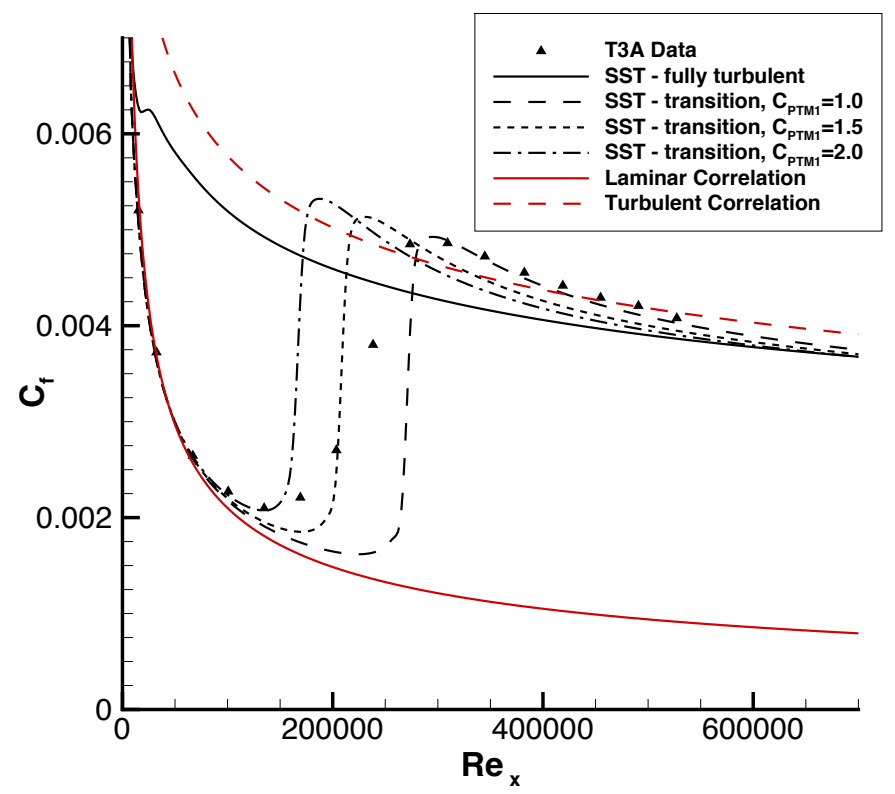

Figure 2. Incompressible transition comparison.

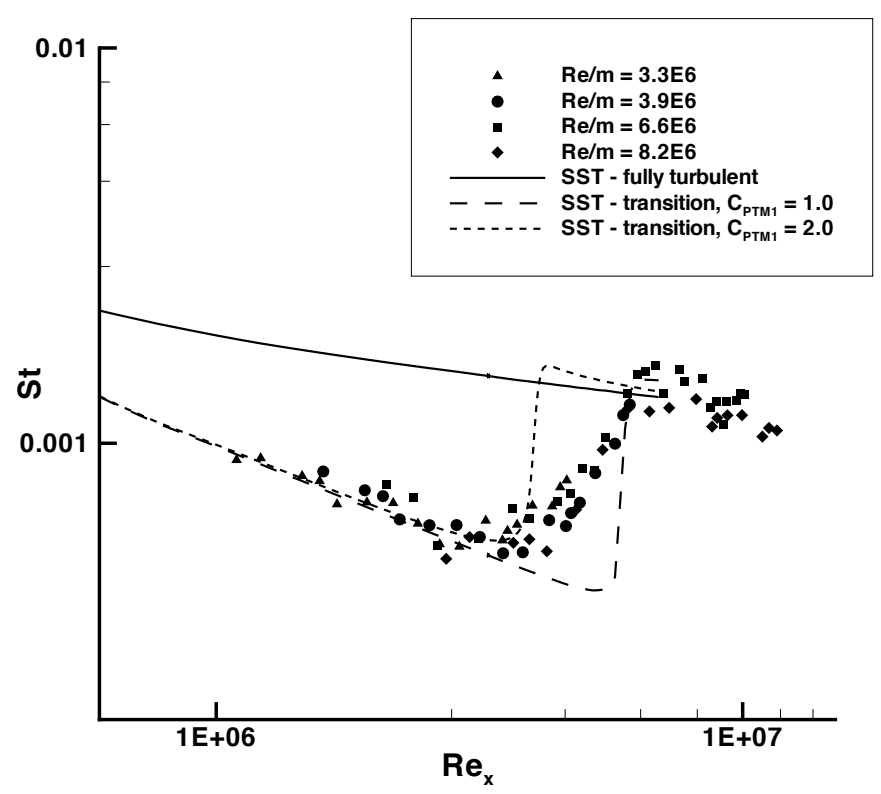

Figure 3. Hypersonic transition comparison. 


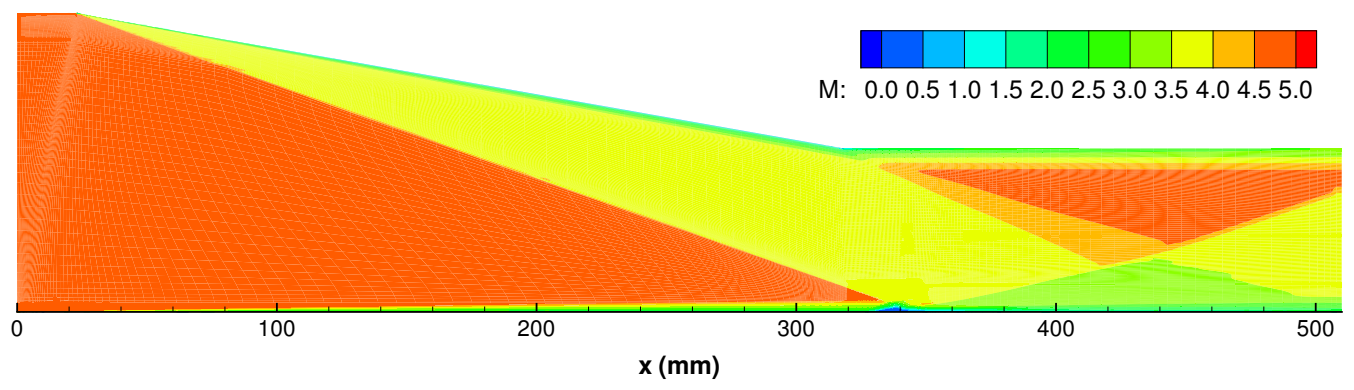

Figure 4. Mach number contours for shock-wave boundary-layer interaction problem.

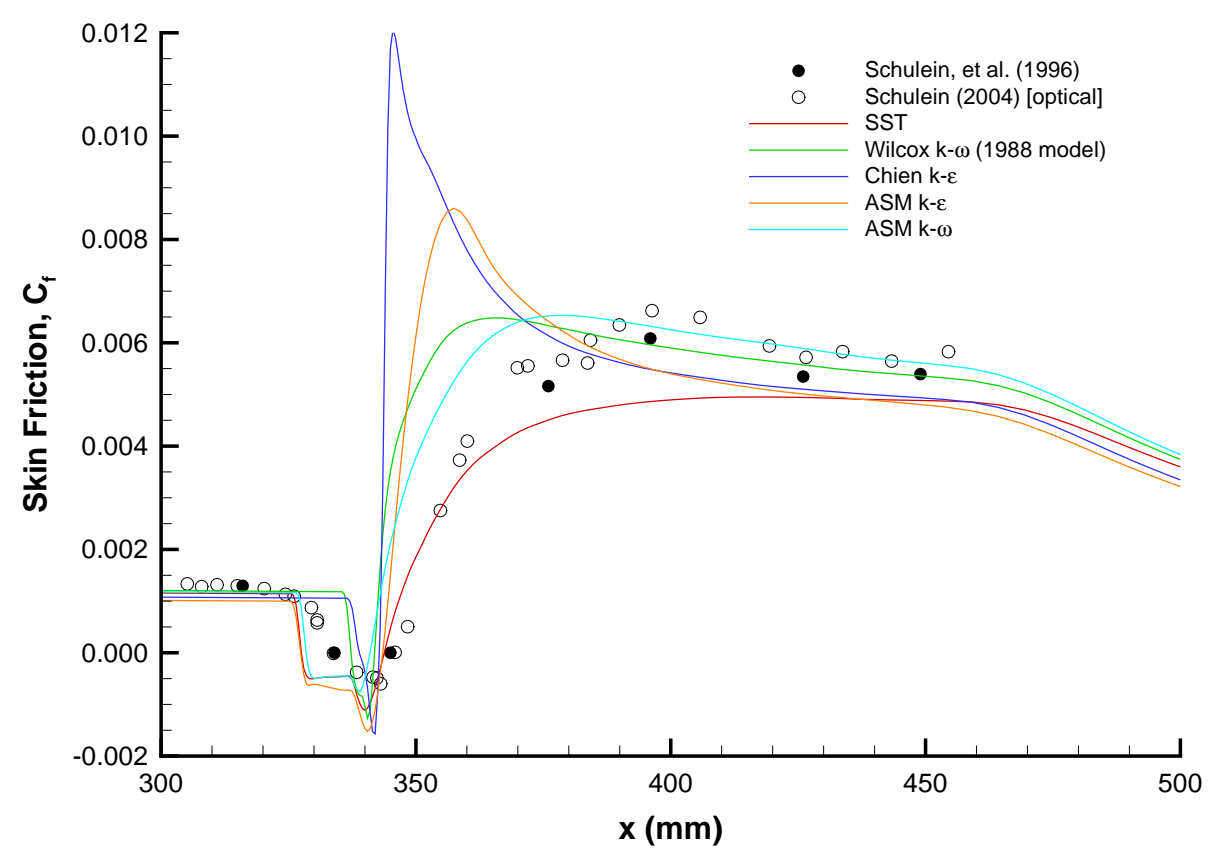

Figure 5. Skin friction along bottom wall for shock-wave boundary-layer interaction problem. 


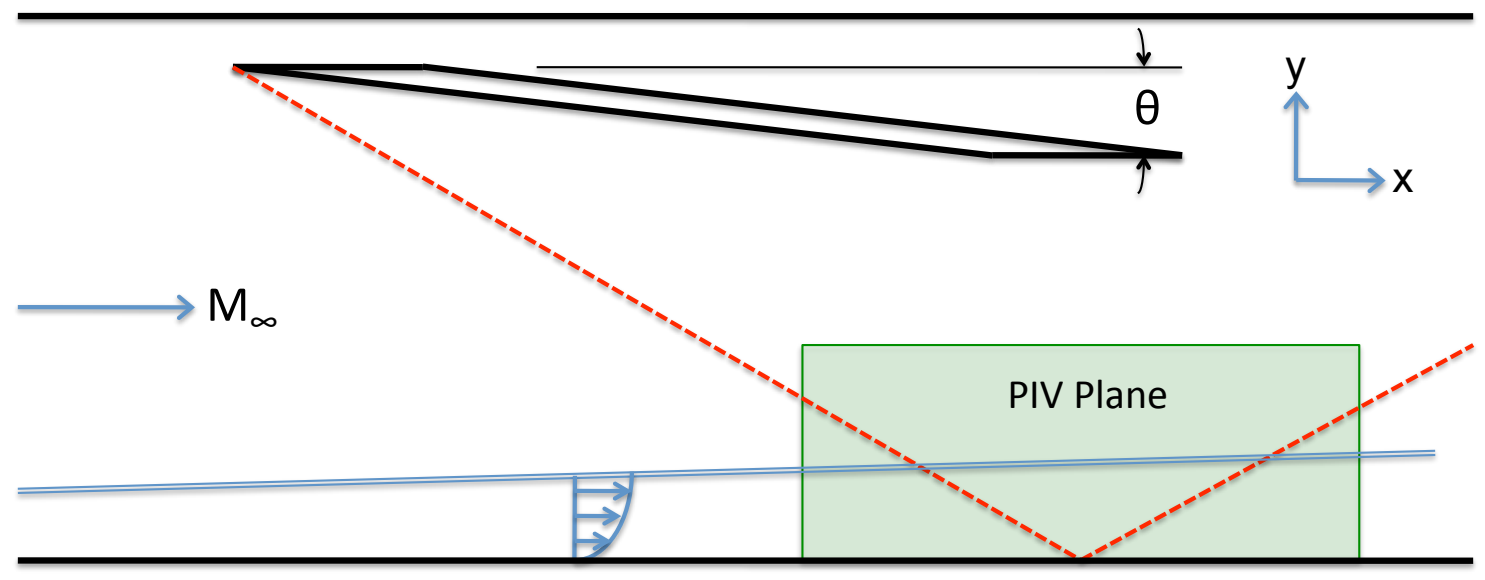

Figure 6. Schematic of typical SWTBLI experimental configuration (courtesy of DeBonis et $\mathrm{al}^{43}$ ).

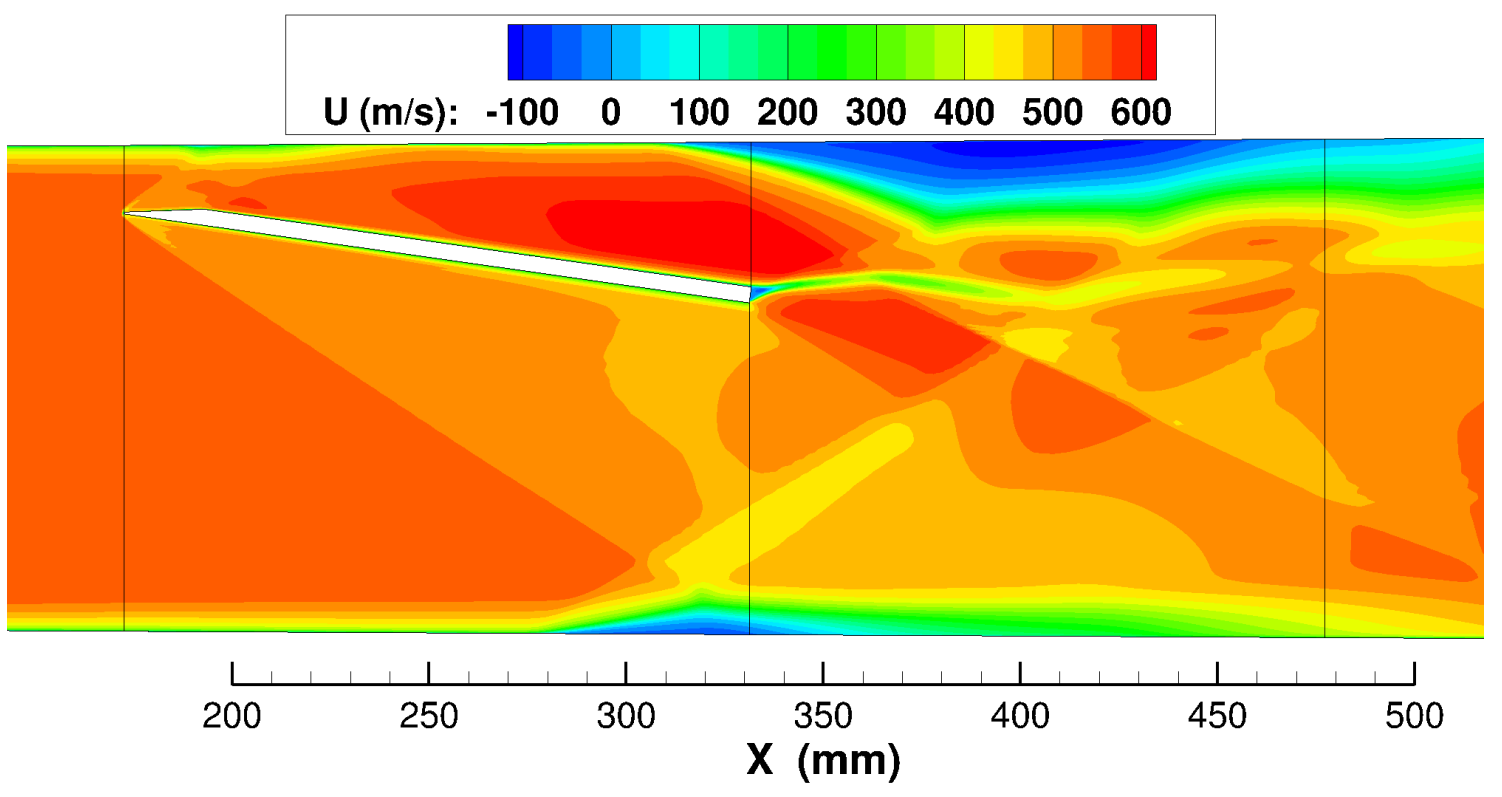

Figure 7. Velocity contours for UFAST test case using SST. 


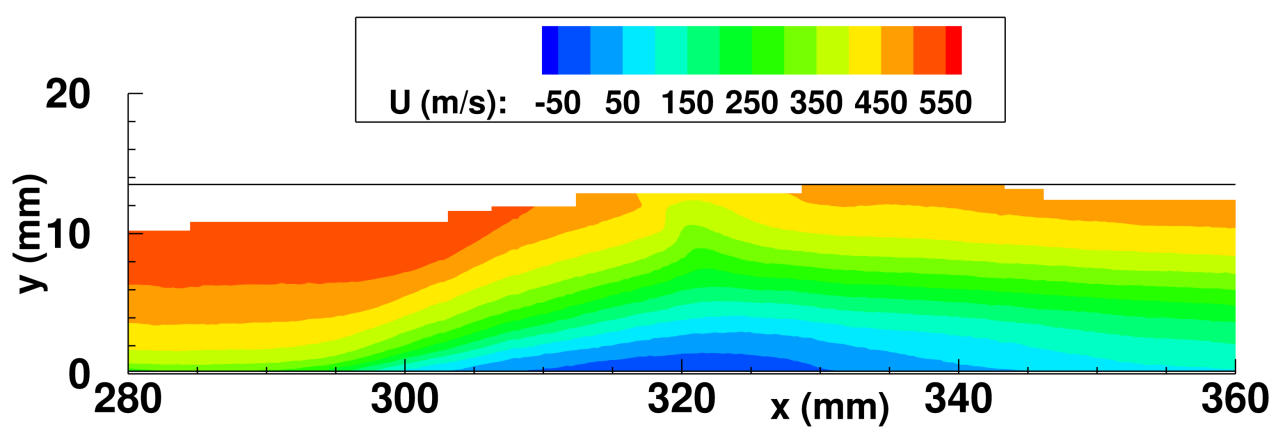

(a) Experiment

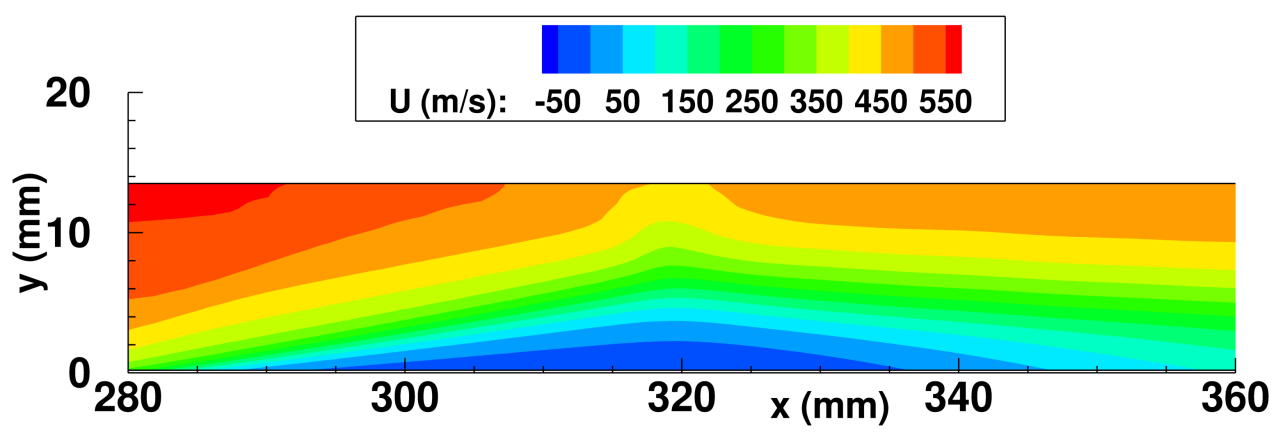

(b) Menter SST

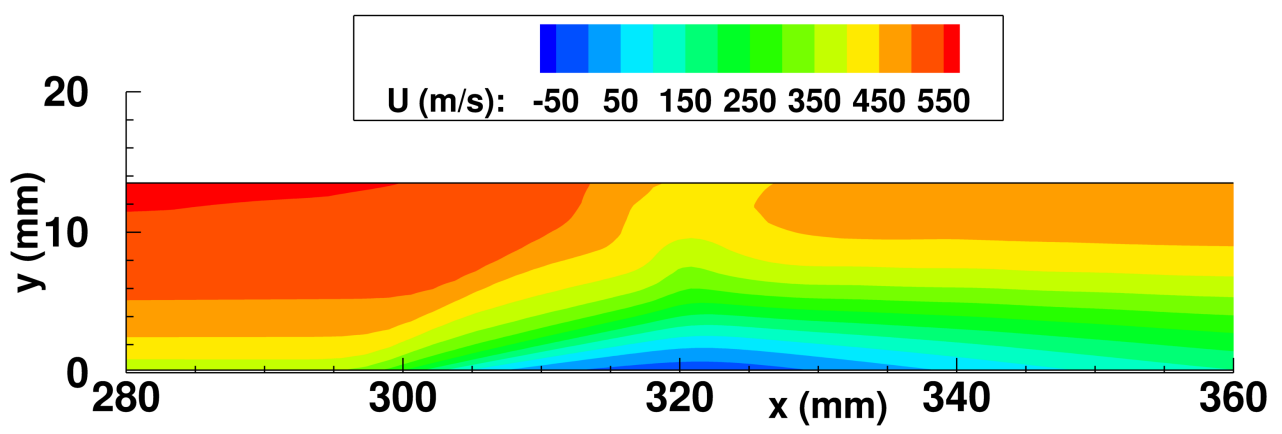

(c) Spalart-Allmaras

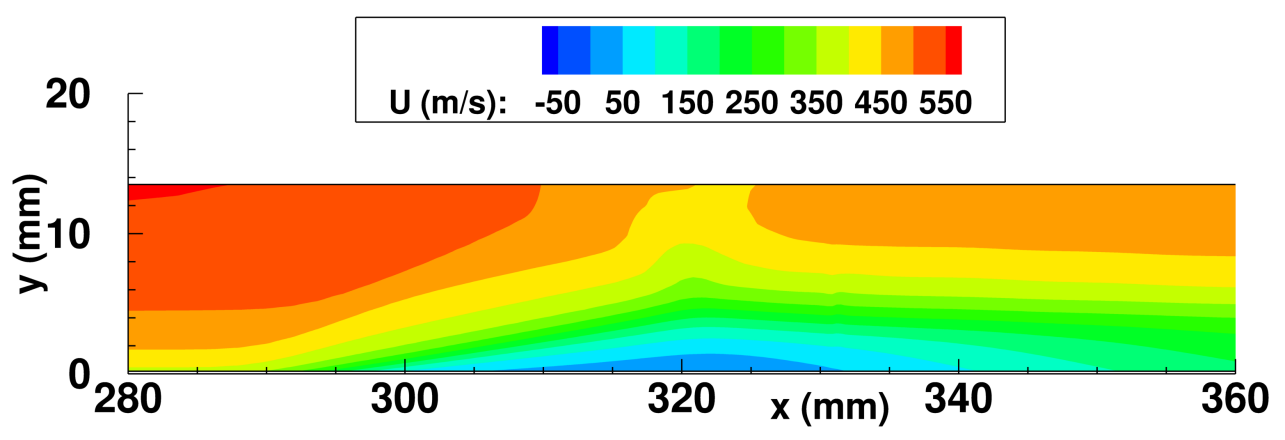

(d) $k-\omega A S M$

Figure 8. Axial velocity contours for UFAST test case in vicinity of SWTBLI. 


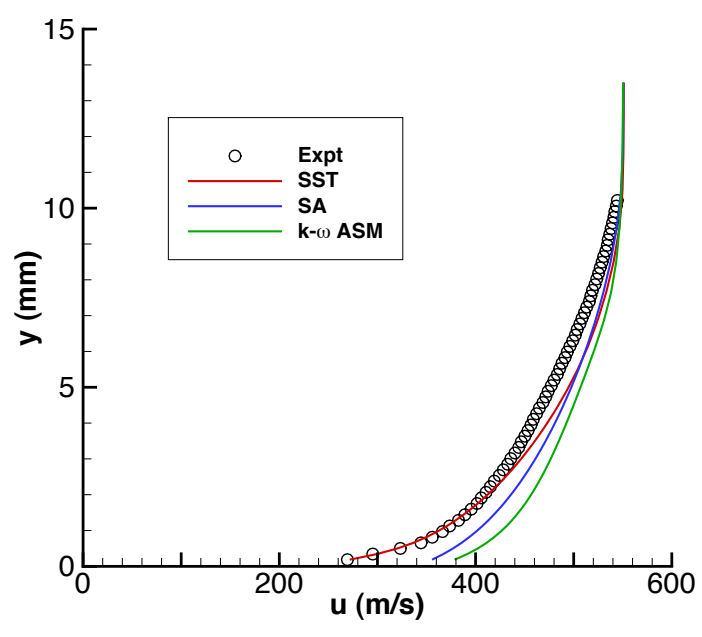

(a) $\mathrm{x}=280 \mathrm{~mm}$

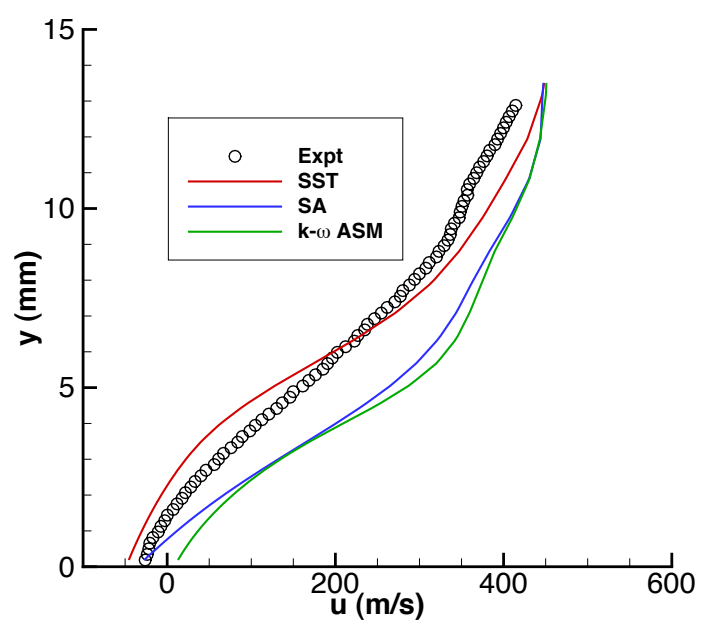

(c) $\mathrm{x}=320 \mathrm{~mm}$

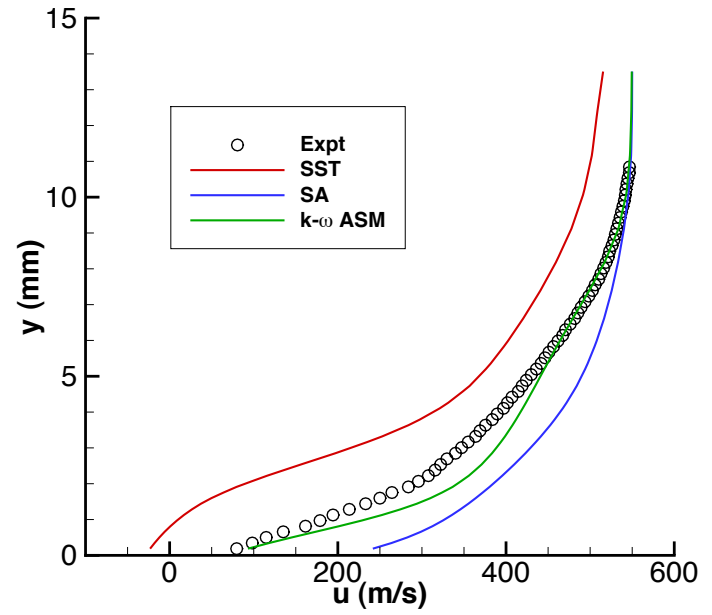

(b) $\mathrm{x}=300 \mathrm{~mm}$

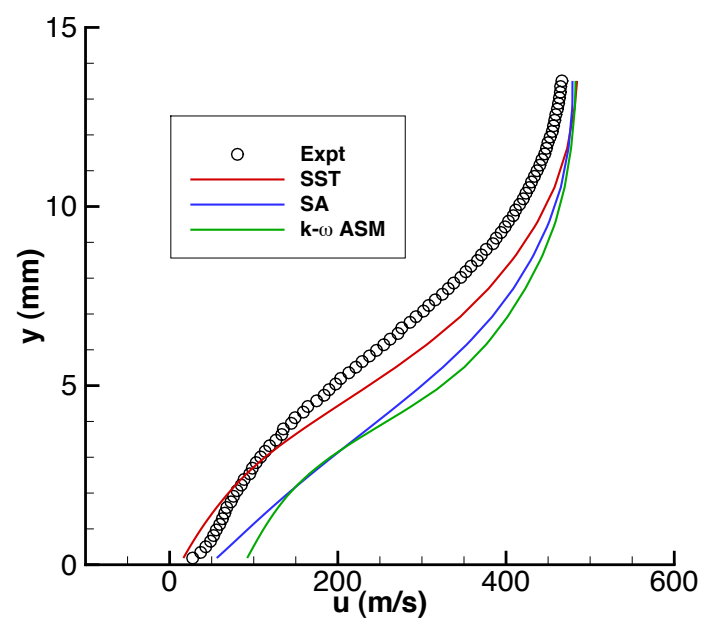

(d) $\mathrm{x}=340 \mathrm{~mm}$

Figure 9. Axial velocity profiles for UFAST test case in vicinity of SWTBLI. 


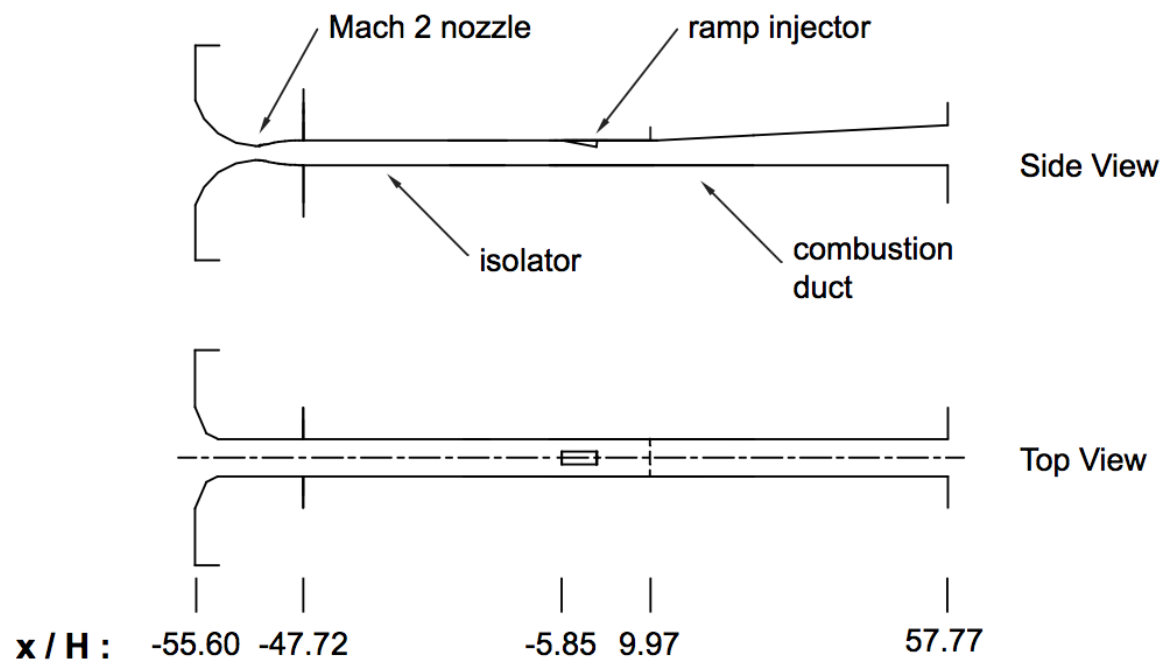

Figure 10. Schematic of UVA direct connect dual-mode combustor (courtesy of Rockwell et $\mathrm{al}^{52}$ ).

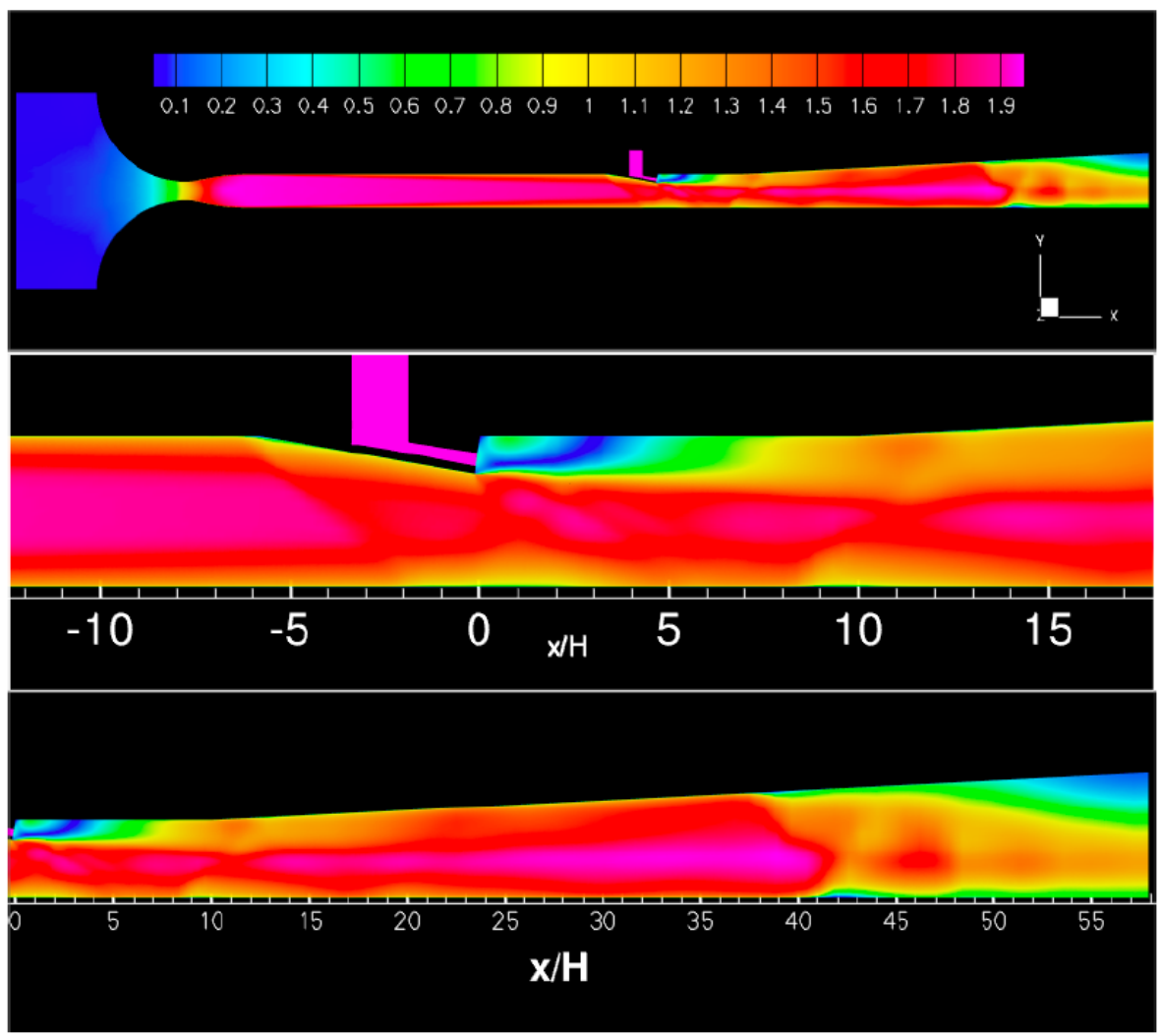

Figure 11. Mach number contours for scramjet flow case, fuel off. 


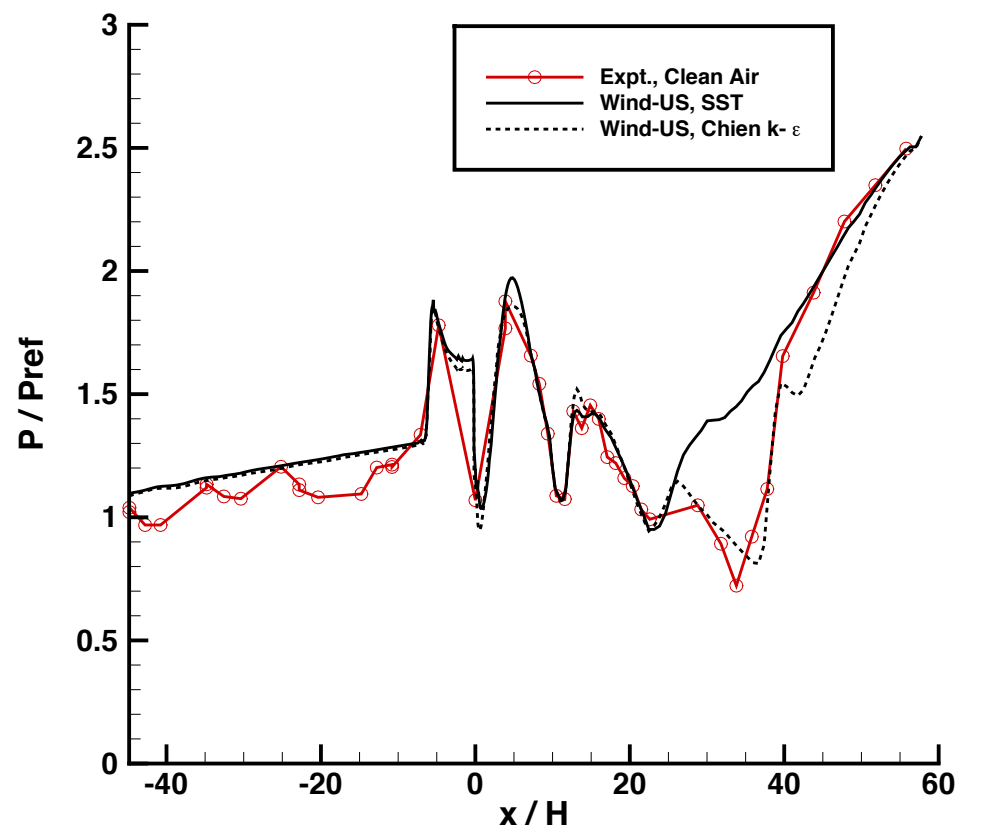

Figure 12. Pressure distributions for scramjet flow case, fuel off. 


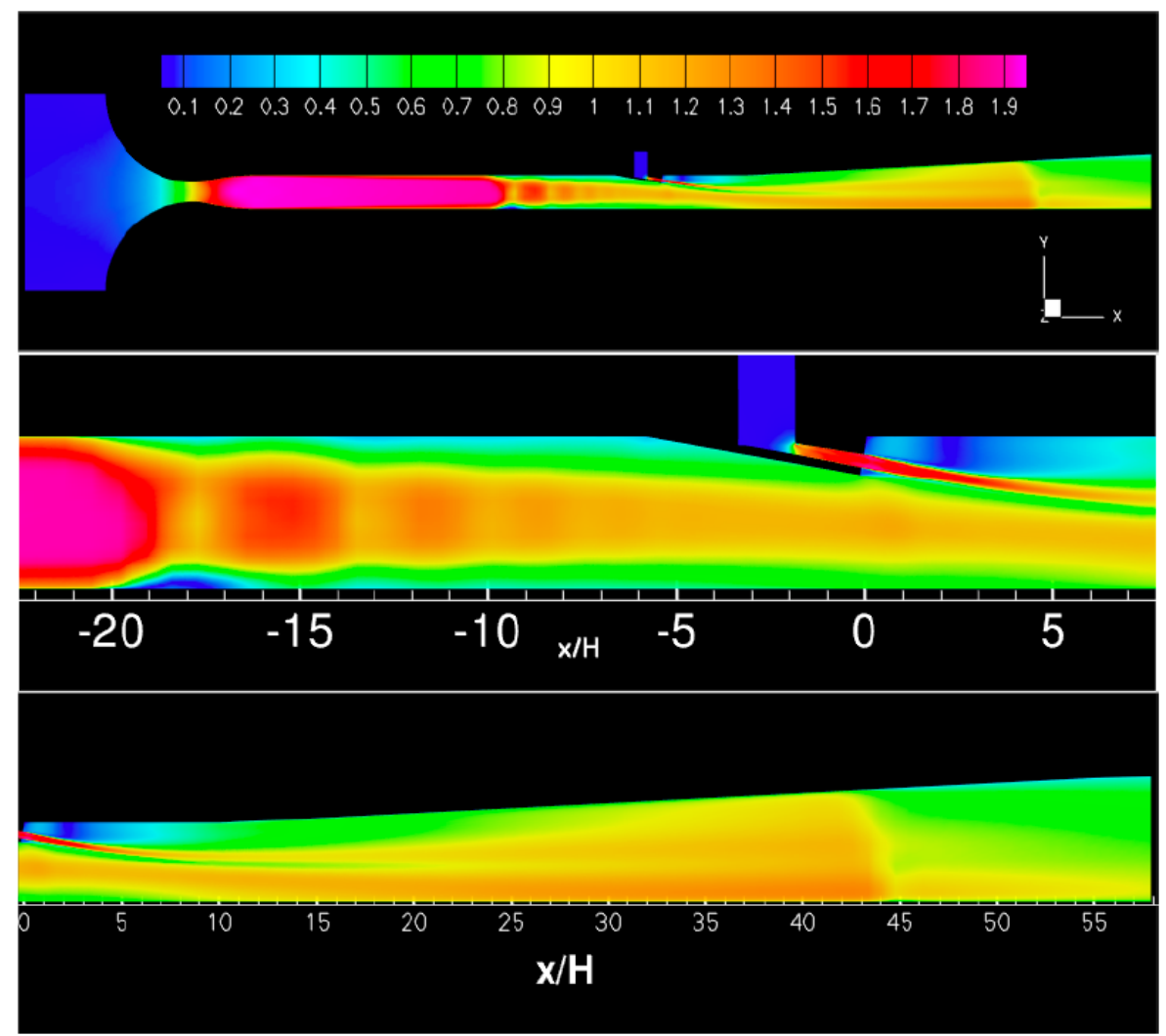

(a) Clean air

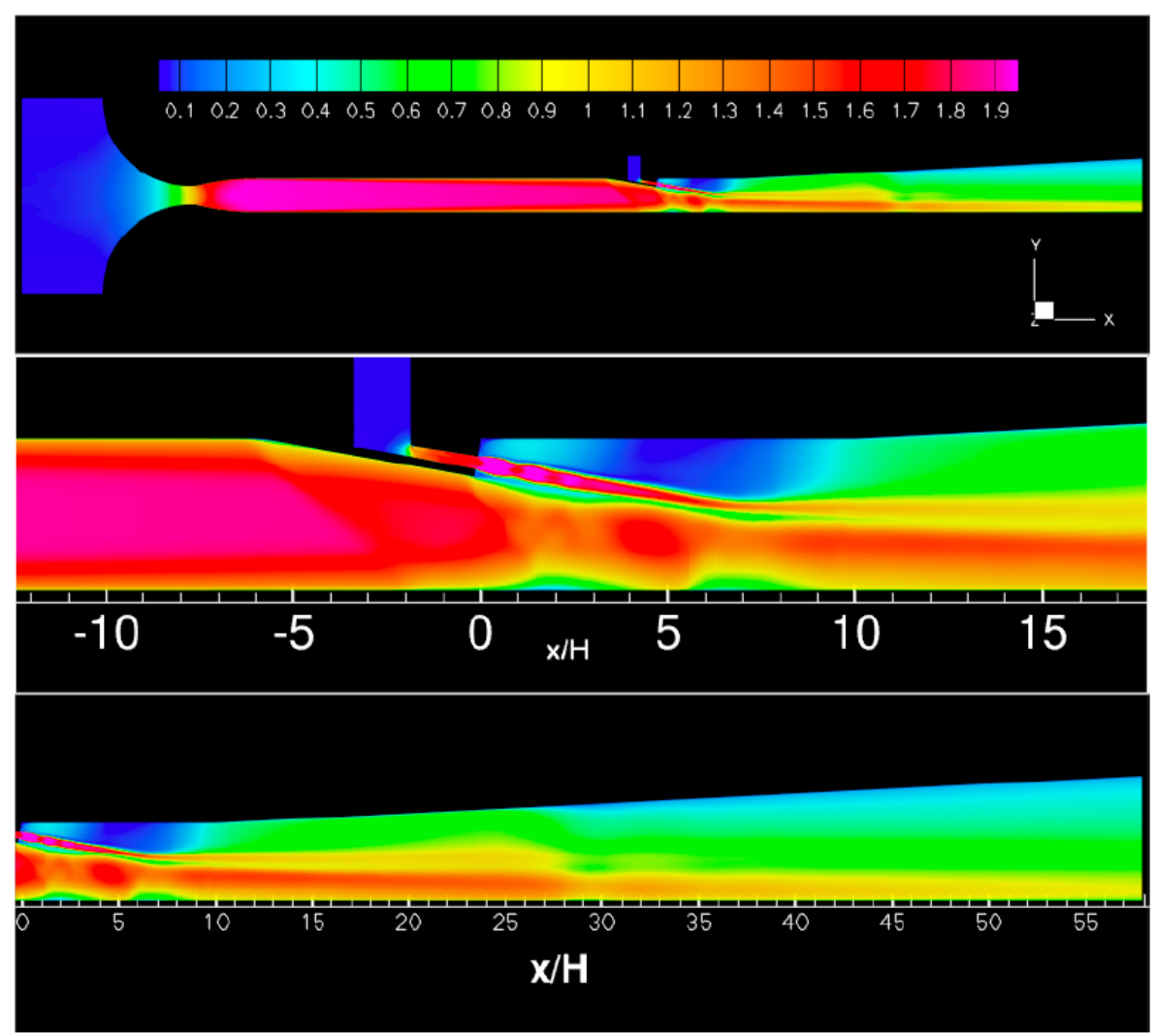

(b) Vitiated air

Figure 13. Mach number contours for scramjet case, $\phi=0.26$. 


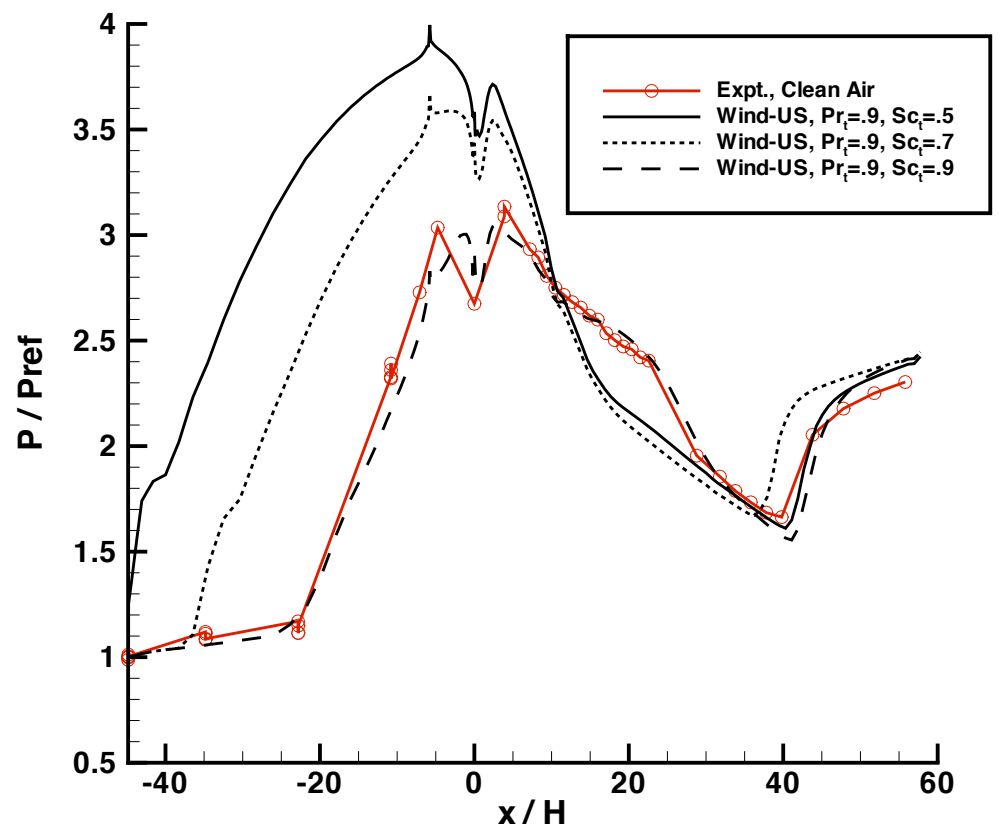

Figure 14. Turbulent Schmidt number effect on clean air scramjet case, $\phi=0.26$.

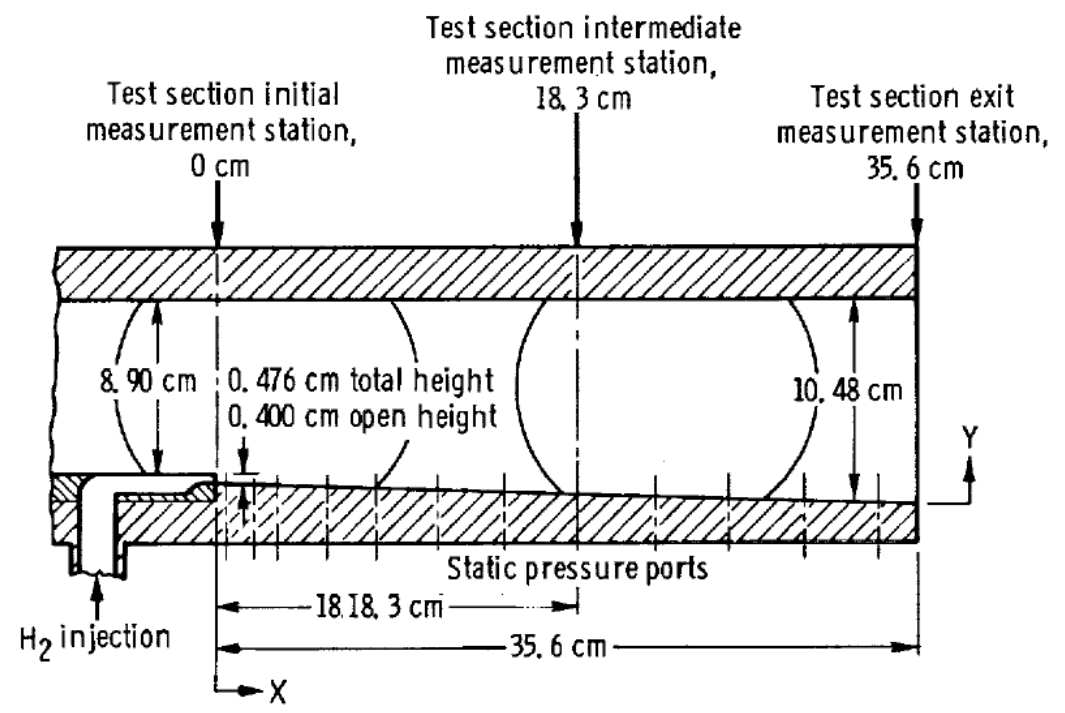

Figure 15. Schematic of Burrows-Kurkov experiment (taken from Burrows and Kurkov ${ }^{60}$ ). 


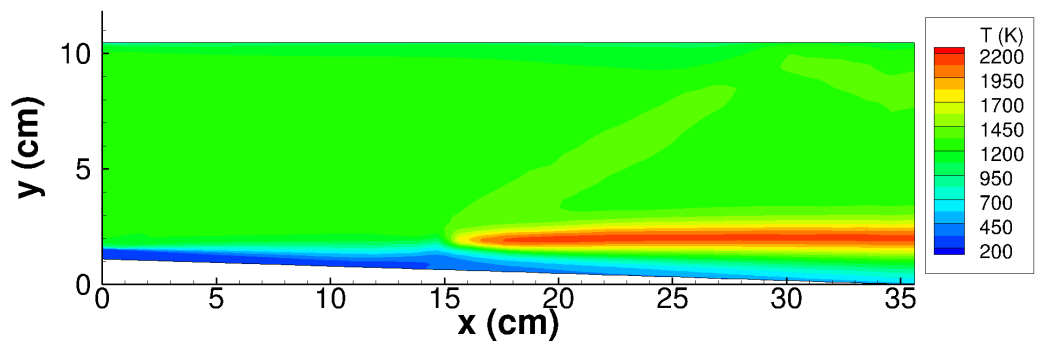

(a) Prt $=0.5$, Sct $=0.7$

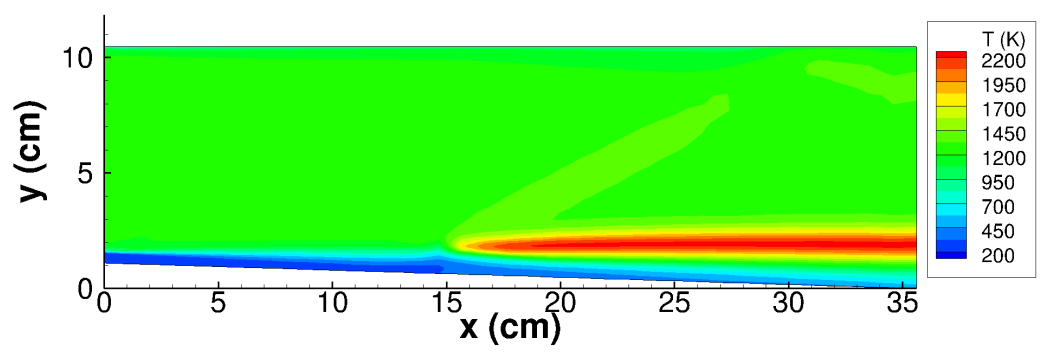

(b) Prt $=0.7$, Sct $=0.7$

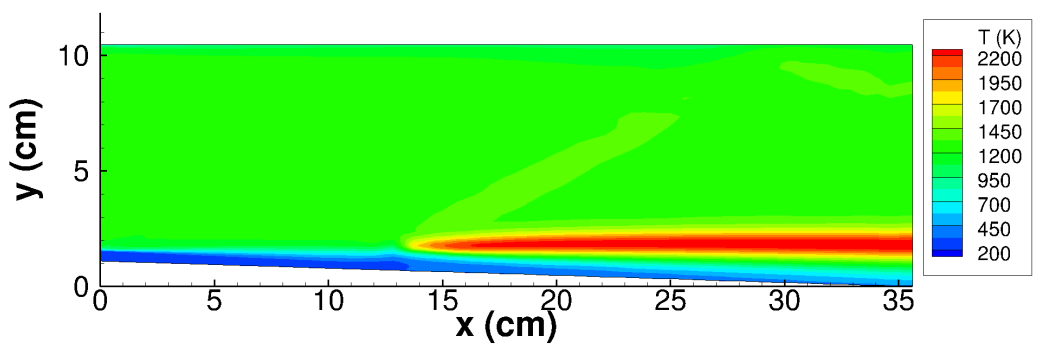

(c) Prt $=0.9$, Sct $=0.7$

Figure 16. Temperature contours for Burrows-Kurkov test case illustrating effect of $\operatorname{Pr}_{t}$ on ignition point. 


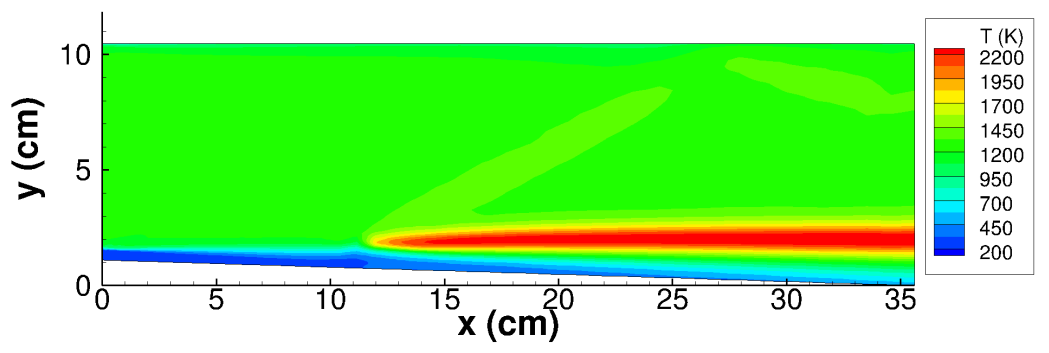

(a) Prt $=0.7$, Sct $=0.5$

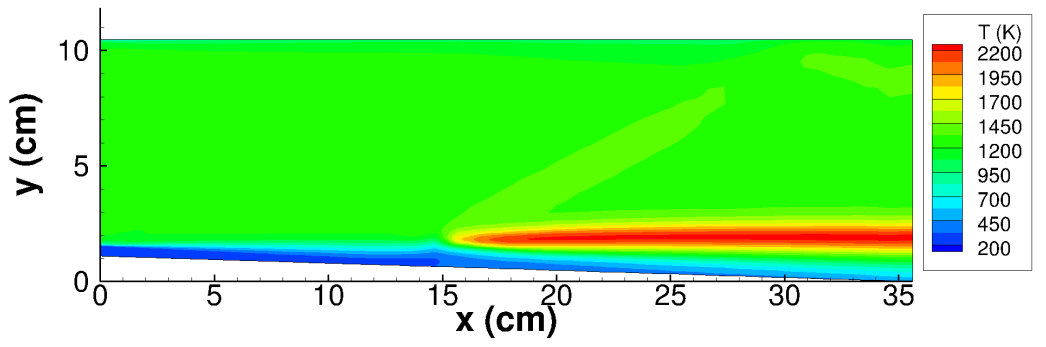

(b) $\operatorname{Prt}=0.7$, Sct $=0.7$

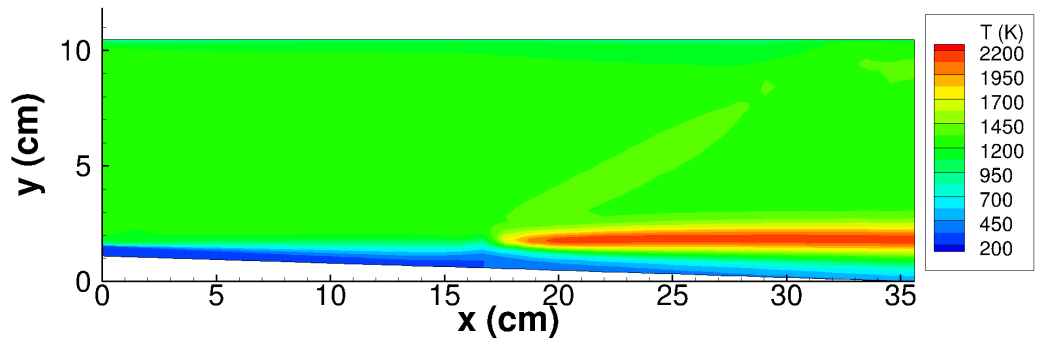

(c) Prt $=0.7$, Sct $=0.9$

Figure 17. Temperature contours for Burrows-Kurkov test case illustrating effect of $S c_{t}$ on ignition point.

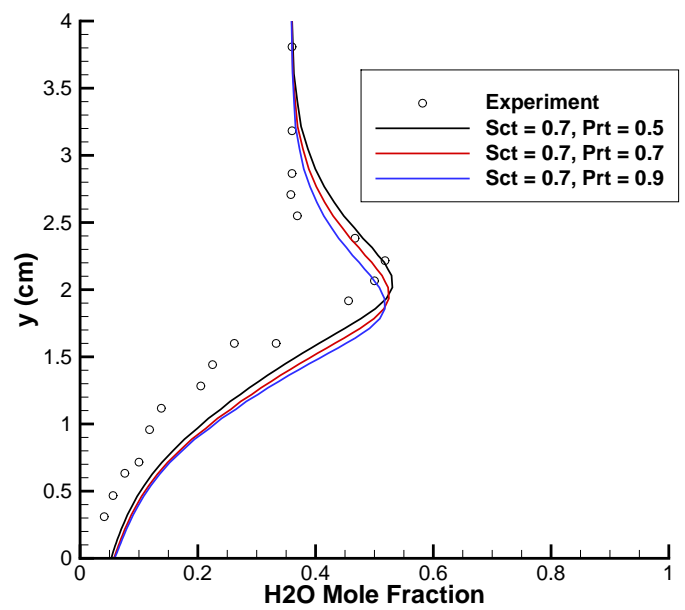

(a) Turbulent Prandtl number variations

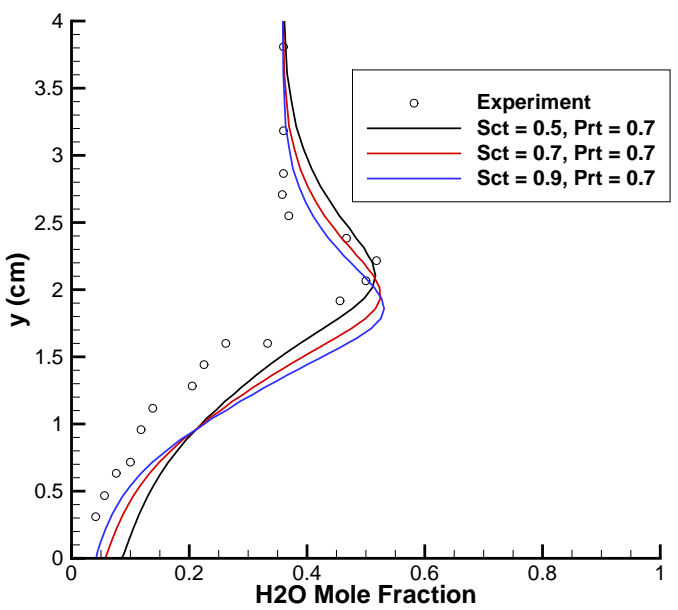

(b) Turbulent Schmidt number variations

Figure 18. Exit profiles for Burrows-Kurkov test case. 


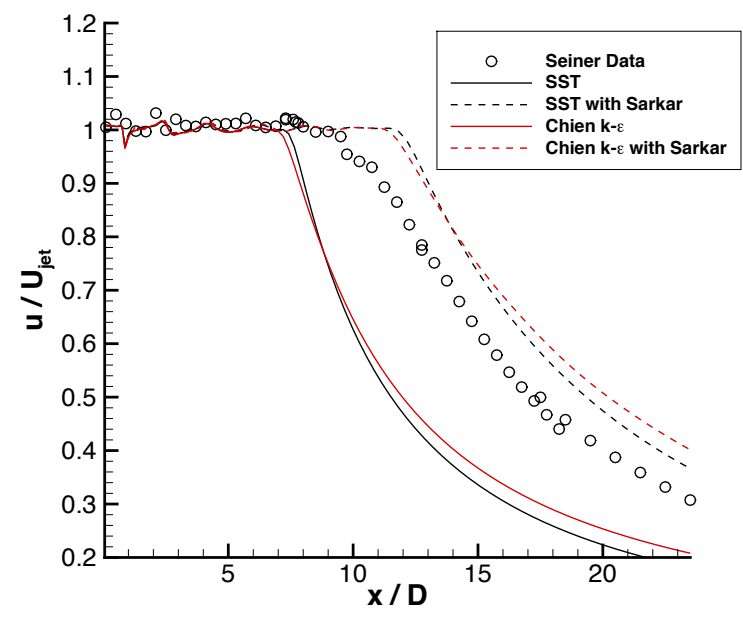

(a) centerline axial velocity

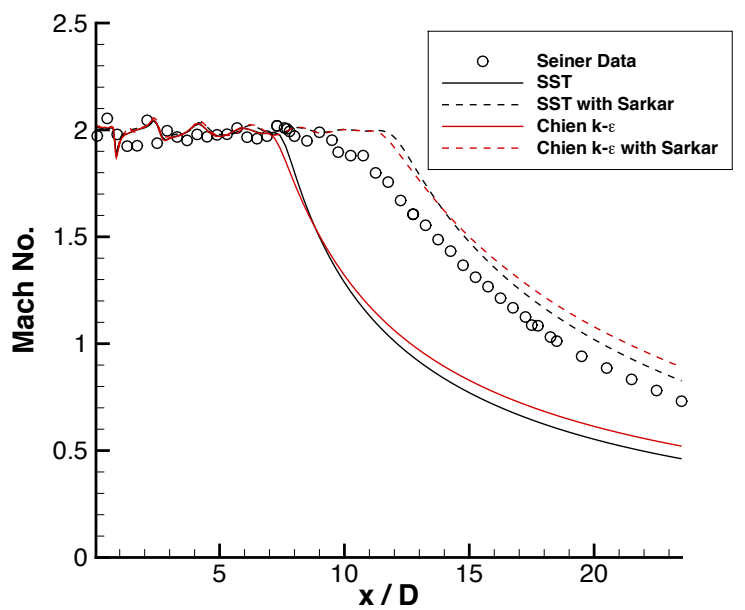

(b) centerline Mach number

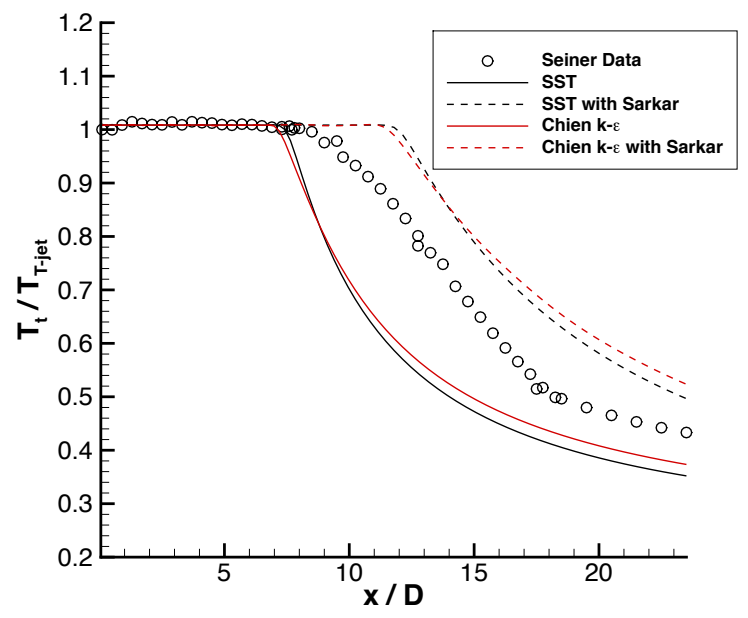

(c) Centerline stagnation temperature

Figure 19. Comparison of solutions for heated Mach 2 jet. 


\begin{tabular}{|c|c|c|}
\hline \multicolumn{2}{|c|}{ REPORT DOCUMENTATION PAGE } & $\begin{array}{l}\text { Form Approved } \\
\text { OMB No. 0704-0188 }\end{array}$ \\
\hline \multicolumn{3}{|c|}{ 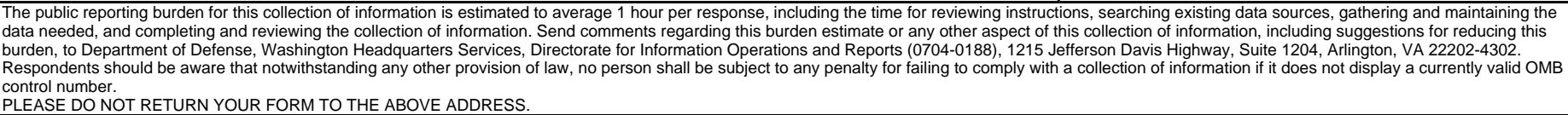 } \\
\hline $\begin{array}{l}\text { 1. REPORT DATE (DD-MM-YYYY) } \\
01-04-2012\end{array}$ & $\begin{array}{l}\text { 2. REPORT TYPE } \\
\text { Technical Memorandum }\end{array}$ & 3. DATES COVERED (From - To) \\
\hline \multirow{3}{*}{\multicolumn{2}{|c|}{$\begin{array}{l}\text { 4. TITLE AND SUBTITLE } \\
\text { Status of Turbulence Modeling for Hypersonic Propulsion Flowpaths }\end{array}$}} & 5a. CONTRACT NUMBER \\
\hline & & 5b. GRANT NUMBER \\
\hline & & 5c. PROGRAM ELEMENT NUMBER \\
\hline \multirow{3}{*}{\multicolumn{2}{|c|}{$\begin{array}{l}\text { 6. AUTHOR(S) } \\
\text { Georgiadis, Nicholas, J.; Yoder, Dennis, A.; Vyas, Manan, A.; Engblom, William, A. }\end{array}$}} & 5d. PROJECT NUMBER \\
\hline & & 5e. TASK NUMBER \\
\hline & & $\begin{array}{l}\text { 5f. WORK UNIT NUMBER } \\
\text { WBS 031102.02.03.0829.11 }\end{array}$ \\
\hline \multicolumn{2}{|c|}{$\begin{array}{l}\text { 7. PERFORMING ORGANIZATION NAME(S) AND ADDRESS(ES) } \\
\text { National Aeronautics and Space Administration } \\
\text { John H. Glenn Research Center at Lewis Field } \\
\text { Cleveland, Ohio 44135-3191 }\end{array}$} & $\begin{array}{l}\text { 8. PERFORMING ORGANIZATION } \\
\text { REPORT NUMBER } \\
\text { E-18032 }\end{array}$ \\
\hline \multirow{2}{*}{\multicolumn{2}{|c|}{$\begin{array}{l}\text { 9. SPONSORING/MONITORING AGENCY NAME(S) AND ADDRESS(ES) } \\
\text { National Aeronautics and Space Administration } \\
\text { Washington, DC 20546-0001 }\end{array}$}} & $\begin{array}{l}\text { 10. SPONSORING/MONITOR'S } \\
\text { ACRONYM(S) } \\
\text { NASA }\end{array}$ \\
\hline & & $\begin{array}{l}\text { 11. SPONSORING/MONITORING } \\
\text { REPORT NUMBER } \\
\text { NASA/TM-2012-217277 }\end{array}$ \\
\hline \multicolumn{3}{|c|}{$\begin{array}{l}\text { 12. DISTRIBUTION/AVAILABILITY STATEMENT } \\
\text { Unclassified-Unlimited } \\
\text { Subject Categories: 01, 02, 07, and } 34 \\
\text { Available electronically at http://www.sti.nasa.gov } \\
\text { This publication is available from the NASA Center for AeroSpace Information, 443-757-5802 }\end{array}$} \\
\hline
\end{tabular}

\section{SUPPLEMENTARY NOTES}

\section{ABSTRACT}

This report provides an assessment of current turbulent flow calculation methods for hypersonic propulsion flowpaths, particularly the scramjet engine. Emphasis is placed on Reynolds-averaged Navier-Stokes (RANS) methods, but some discussion of newer meth- ods such as Large Eddy Simulation (LES) is also provided. The report is organized by considering technical issues throughout the scramjet-powered vehicle flowpath including laminar-to-turbulent boundary layer transition, shock wave / turbulent boundary layer interactions, scalar transport modeling (specifically the significance of turbulent Prandtl and Schmidt numbers) and compressible mixing. Unit problems are primarily used to conduct the assessment. In the combustor, results from calculations of a direct connect supersonic combustion experiment are also used to address the effects of turbulence model selection and in particular settings for the turbulent Prandtl and Schmidt numbers. It is concluded that RANS turbulence modeling shortfalls are still a major limitation to the accuracy of hypersonic propulsion simulations, whether considering individual components or an overall system. Newer methods such as LES-based techniques may be promising, but are not yet at a maturity to be used routinely by the hypersonic propulsion community. The need for fundamental experiments to provide data for turbulence model development and validation is discussed.

\section{SUBJECT TERMS}

Hypersonics; Turbulence; Transition; Heat transfer; Scramjet; Large Eddy Simulation (LES)

\begin{tabular}{|c|c|c|c|c|}
\hline \multicolumn{3}{|c|}{ 16. SECURITY CLASSIFICATION OF: } & \multirow{2}{*}{$\begin{array}{l}\text { 17. LIMITATION OF } \\
\text { ABSTRACT } \\
\text { UU }\end{array}$} & \multirow{2}{*}{$\begin{array}{l}\text { 18. NUMBER } \\
\text { OF } \\
\text { PAGES } \\
34\end{array}$} \\
\hline $\begin{array}{l}\text { a. REPORT } \\
U\end{array}$ & $\begin{array}{l}\text { b. ABSTRACT } \\
\text { U }\end{array}$ & $\begin{array}{l}\text { c. THIS } \\
\text { PAGE } \\
\text { U }\end{array}$ & & \\
\hline
\end{tabular}


